\title{
Epigallocatechin-3-gallate Attenuates Renal Damage by Suppressing Oxidative Stress in Diabetic db/db Mice
}

\author{
Xiu Hong Yang, ${ }^{1}$ Yu Pan, ${ }^{2}$ Xiao Li Zhan, ${ }^{1}$ Bao Long Zhang, ${ }^{3}$ Li Li Guo, ${ }^{4}$ and Hui Min Jin ${ }^{1}$ \\ ${ }^{1}$ Division of Nephrology, Shanghai Pudong Hospital, Fudan University Pudong Medical Center, 2800 Gong Wei Road, Shanghai, China \\ ${ }^{2}$ Division of Nephrology, Shanghai No. 9 People's Hospital, Shanghai Jiao Tong University School of Medicine, Shanghai, China \\ ${ }^{3}$ The Institutes of Biomedical Sciences (IBS), Fudan University, Shanghai, China \\ ${ }^{4}$ Hemodialysis Center, Bao Shan Branch of No. 1 People's Hospital, Shanghai Jiao Tong University, Shanghai, China
}

Correspondence should be addressed to Li Li Guo; gflmei@hotmail.com and Hui Min Jin; hmjgli@163.com

Received 22 May 2016; Revised 14 July 2016; Accepted 9 August 2016

Academic Editor: Claudio Cabello-Verrugio

Copyright (c) 2016 Xiu Hong Yang et al. This is an open access article distributed under the Creative Commons Attribution License, which permits unrestricted use, distribution, and reproduction in any medium, provided the original work is properly cited.

\begin{abstract}
Epigallocatechin-3-gallate (EGCG), extracted from green tea, has been shown to have antioxidative activity. In the present study, we evaluated the effect of EGCG on the kidney function in $\mathrm{db} / \mathrm{db}$ mice and also tried to investigate the underlying mechanism of the renoprotective effects of EGCG in both animals and cells. EGCG treatment could decrease the level of urinary protein, 8-isoPGF2a, and Ang II. Moreover, EGCG could also change the level of several parameters associated with oxidative stress. In addition, the protein expression levels of AT-1R, p22-phox, p47-phox, p-ERK1/2, p-p38 MAPK, TGF- $\beta 1$, and $\alpha$-SMA in diabetic db/db mice were upregulated, and all of these symptoms were downregulated with the treatment of EGCG at 50 and $100 \mathrm{mg} / \mathrm{kg} / \mathrm{d}$. Furthermore, the pathological changes were ameliorated in $\mathrm{db} / \mathrm{db}$ mice after EGCG treatment. HK-2 cell-based experiments indicated that EGCG could inhibit the expression of MAPK pathways, which is the downstream effector of Ang II mediated oxidative stress. All these results indicated that EGCG treatment could ameliorate changes of renal pathology and delay the progression of DKD by suppressing hyperglycemia-induced oxidative stress in diabetic $\mathrm{db} / \mathrm{db}$ mice.
\end{abstract}

\section{Introduction}

Based on the survey of International Diabetes Federation (IDF), the number of people with diabetes mellitus (DM) was as high as 415.0 million in 2015 all over the world [1]. In China, there are more than 98.4 million patients with diabetes in 2013, ranking first in the world, and the number is estimated to reach 143.0 million in 2035 [1]. Diabetes, a worldwide health problem, is defined as a group of metabolic diseases characterized by hyperglycemia. Diabetes is always associated with long-term damage, dysfunction, and failure of different organs, leading to the development of several complications $[2,3]$. Diabetic kidney disease (DKD) is a kind of chronic microvascular complications associated with diabetes, and $40 \%$ or more diabetic patients have developed DKD despite current treatments $[2,3]$. DKD is also a major cause of chronic renal failure $[2,3]$. Therefore, it is of great importance to find new approaches to delay the progression of DKD so as to reduce the number of dialysis patients.

Several recent studies have suggested that oxidative stress is involved in the procession and development of kidney injury, including DKD $[2,4-6]$. Oxidative stress refers to the increase of reactive oxygen species (ROS) production and/or the decrease of antioxidant production disordering the balance between oxidation and antioxidation, leading to renal injury $[2,6]$. Through multiple mechanisms, ROS can cause kidney damage, such as inducing the expression of angiotensin II (Ang II), increasing the production of transforming growth factor- $\beta 1$ (TGF- $\beta 1$ ) and smooth muscle actin- $\alpha$ ( $\alpha$-SMA), and activating the mitogen-activated protein kinase (MAPK) cascade [7-12]. In addition, it has been demonstrated that the major source for the generation of ROS is nicotinamide adenine dinucleotide phosphate (NADPH) oxidase in diabetic conditions $[5,6,13-15]$. As reported 
previously, NADPH oxidase inhibitor can effectively restrain ROS generation, reduce the level of urinary protein, ameliorate the pathological changes of kidney, and delay the progression of DKD in the type 2 diabetic rat model [13].

Drinking tea is a common habit for Chinese people, which has a long history in China. Epigallocatechin-3-gallate (EGCG), a kind of green tea extract, is the major polyphenolic constituent present in green tea. Since it has been suggested to have anti-inflammatory, antioxidative, and hypoglycemic effects, EGCG has become a research hotpot in recent years [16-19]. But EGCG has been shown to exert prooxidative activities in some other studies [20,21]. To date, a variety of studies have demonstrated that EGCG has salutary effects, but the precise mechanisms of EGCG are still unclear in DKD.

Therefore, we performed the present study to evaluate the effect of EGCG on the kidney function in $\mathrm{db} / \mathrm{db}$ mice. Additionally, we also tried to investigate the underlying mechanism of the renoprotective effects of EGCG in both animals and cells.

\section{Materials and Methods}

2.1. Animals and Experimental Groups. Eight-week-old C57BLKS/J db/db mice (type 2 diabetic mice model) and their normal mice were purchased from Model Animal Research Center of Nanjing University (Nanjing, Jiangsu, China). The average weight of $\mathrm{db} / \mathrm{db}$ mice was $33.7 \pm 1.5 \mathrm{~g}$. All the animal experimental procedures were approved by the Animal Care Committee of Fudan University. Mice were housed in plastic cages with a controlled temperature of $23-26^{\circ} \mathrm{C}$, humidity of $50-55 \%$, and a $12 \mathrm{~h}$ light/dark cycle. All the mice had free access to food and distilled water.

EGCG (>90\% purity) was obtained from Sigma-Aldrich (St. Louis, MO, USA). Then Mice were allocated into 4 groups with the following treatment ( $n=16$, each): (1) normal, C57BLKS/J normal nontreated mice (gavage administration of $0.9 \%$ saline); (2) control, C57BLKS/J db/db nontreated mice (gavage administration of $0.9 \%$ saline); (3) EGCG A, C57BLKS/J db/db treated mice (gavage administration of EGCG $50 \mathrm{mg} / \mathrm{kg} / \mathrm{d}$ ); and (4) EGCG B, C57BLKS/J db/db treated mice (gavage administration of EGCG $100 \mathrm{mg} / \mathrm{kg} / \mathrm{d}$ ). The doses of EGCG were based on the previous researches [22]. Mice were sacrificed at week 4 and at week 8 , with 8 animals killed each time in each group, respectively.

2.2. Oral Glucose Tolerance Test (OGTT). After fasting for $16 \mathrm{~h}$, a basal blood sample was collected from the tip of the tail of mice $(t=0 \mathrm{~min})$. Then mice from all groups were subjected to an OGTT. Briefly, animals were given glucose $(1 \mathrm{~g} / \mathrm{kg})$ by gavage and blood samples were collected from the tail vein of mice at $0,15,30,60,90$, and 120 minutes after administration for the measurement of glucose. Fasting blood glucose concentration was measured with the OneTouch Basic glucose meter (LifeScan Canada Ltd., Burnaby, BC, Canada) and fasting plasma insulin was measured with mouse insulin ELISA kits (Crystal Chem, Downers Grove, IL, USA).
2.3. Measurement of Urine Protein, 8-Iso-prostaglandin F2 $\alpha$ (8-Iso-PGF2a), and Ang II in the Renal Homogenate. Mice, one per metabolic cage, were placed for $24 \mathrm{~h}$ urine collection. Urine samples from all mice were centrifuged at $12000 \mathrm{rpm}$ for 5 minutes. Then, the clear supernatant from urine samples was collected and stored at $-80^{\circ} \mathrm{C}$ for further analysis. The 24-hour urinary protein was determined by Coomassie Blue Plus Protein Assay Kit (Pierce, Rockford, IL, USA). Moreover, renal Ang II concentration was measured with Mouse Angiotensin II Elisa Kit, which was obtained from USCN Life Science, Inc. (Wuhan, Hubei, China). Furthermore, 8-isoPGF2a concentration in urine was measured by a commercial ELISA kit (Cayman, Ann Arbor, MI, USA).

2.4. Measurement of Reactive Oxygen Species (ROS), 8Hydroxy-2'-deoxyguanosine (8-OHdG), Superoxide Dismutase (SOD), Malondialdehyde (MDA), Catalase (CAT), and 3-Nitrotyrosine Concentration in Kidney Homogenates. After animals were killed, the kidney was excised immediately and placed in ice-cold RIPA buffer (CST, Beverly, MA, USA) for homogenization using a tissue homogenizer. After centrifugation, supernatant was collected and used for analysis of generation of following parameters in kidney homogenates: ROS level was detected by a fluorometric assay using the $2^{\prime} 7^{\prime}$ dichlorodihydrofluorescein diacetate (DCFH-DA, SigmaAldrich, St. Louis, MO, USA) as a fluorescence probe; the levels of SOD, MDA, CAT, and 8-OHdG in kidney were measured with commercial kits (Nanjing Jiancheng, Nanjing, Jiangsu, China); and 3-nitrotyrosine, a marker for oxidative stress in the kidney, was detected by ELISA using a commercial kit (Millipore, Bedford, MA, USA).

2.5. Cell Cultures and Treatments. HK-2 cells, a line of human renal proximal tubular epithelial cells obtained from Bioresource Collection and Research Center (BCRC), were maintained in Dulbecco's modified Eagle's medium (DMEM; Invitrogen, Carlsbad, CA, USA) supplemented with 10\% fetal bovine serum (FBS, HyClone, South Logan, UT, USA) and $2 \%$ antibiotics (HyClone, South Logan, UT, USA). The medium was changed every three days. When HK-2 cells grew to $80 \%$ confluence, they were cultured in serum-free medium for $24 \mathrm{~h}$.

To investigate the underlying mechanism of renoprotective effects of EGCG, cells were randomly divided into 4 groups: (1) untreated group, (2) Ang II group (cells were treated with $1 \mu \mathrm{M}$ Ang II), (3) Ang II + EGCG A group (cells were first treated with $15 \mu \mathrm{M}$ EGCG for $6 \mathrm{~h}$, followed by $1 \mu \mathrm{M}$ Ang II for $24 \mathrm{~h}$ ), and (4) Ang II + EGCG B group (cells were first treated with $30 \mu \mathrm{M}$ EGCG for $6 \mathrm{~h}$, followed by $1 \mu \mathrm{M}$ Ang II for $24 \mathrm{~h}$ ). In addition, we also explored the role of PD98059 (ERK1/2 inhibitor, Sigma-Aldrich, St Louis, MO, USA) and SB202190 (p38 MAPK inhibitor, Sigma-Aldrich, St Louis, MO, USA) in Ang II mediated renal fibrosis; cells were then divided into five groups: (1) untreated group, (2) Ang II group (cells were treated with $1 \mu \mathrm{M}$ Ang II), (3) Ang II + PD98059 group (cells were first treated with $10 \mathrm{mM}$ PD98059 for $6 \mathrm{~h}$, followed by $1 \mu \mathrm{M}$ Ang II for $24 \mathrm{~h}$ ), (4) Ang II + SB202190

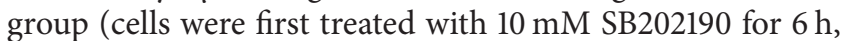
followed by $1 \mu \mathrm{M}$ Ang II for $24 \mathrm{~h}$ ), and (5) Ang II + both 
groups (cells were first treated with $10 \mathrm{mM}$ SB202190 and $10 \mathrm{mM}$ PD98059 for $6 \mathrm{~h}$, followed by $1 \mu \mathrm{M}$ Ang II for $24 \mathrm{~h}$ Ang II). The doses of Ang II, EGCG, PD98059, and SB202190 were based on the previous researches $[23,24]$.

2.6. Western Blot Analysis. All protein samples of both kidney tissue and cultured HK-2 cells were centrifuged at $14000 \mathrm{rpm}$ for 10 minutes, and the clear supernatants were collected. Total protein concentrations in the supernatants were determined by the BCA method. Then, the protein was boiled at $98^{\circ} \mathrm{C}$ for 5 to 10 minutes and stored at $-80^{\circ} \mathrm{C}$ for later analysis.

Total of $45 \mu \mathrm{g}$ protein (per sample) was electrophoresed via 10 or $12 \%$ SDS-PAGE and transferred onto nitrocellulose membranes (Bio-Rad, CA, USA). The membranes were then blocked with $5 \%$ nonfat milk or $5 \%$ BAS (bovine serum albumin) power and blocking buffer (1x Tris buffered saline and $0.1 \%$ Tween 20, Ph 7.4) at room temperature for 1 hour and next incubated with rabbit-anti-mouse primary antibodies overnight at $4^{\circ} \mathrm{C}$ : Ang II type 1 receptor (AT-1R, 1:1000), NADPH oxidase 1 (NOX-1, 1:1000), NOX-4 (1:1000), p22phox $(1: 1000)$, p47-phox $(1: 1000)$, extracellular regulated protein kinases 1/2 (ERK1/2, 1:1000), p-ERK1/2 (1:1000), p38 MAPK (1:1000), p-p38 MAPK (1:500), TGF- $\beta 1$ (1:100), $\alpha$-SMA $(1: 100)$, and GAPDH $(1: 1000)$. The next day, after washing with Tris buffered saline for three times for $30 \mathrm{~min}$ utes (changed every 10 minutes), the membranes were incubated for 1 hour at room temperature with secondary antibodies (horseradish peroxidase-conjugated anti-rabbit IgG, $1: 2000)$. For Western blot, the primary antibodies against AT-1R, p22-phox, p47-phox, TGF- $\beta 1, \alpha$-SMA, and GAPDH were purchased from Santa Cruz Biotechnology (Santa Cruz, CA, USA); those against p-ERK1/2, ERK1/2, p-p38 MAPK, p38 MAPK, and secondary antibodies were obtained from Cell Signaling Technology, Inc. (Beverly, MA, USA); antibodies against NOX1 and NOX4 were obtained from Abcam Company (Cambridge, MA, USA). Finally, the protein bands were visualized using SuperSignal West Femto Substrate (Pierce, Rockford, IL, USA).

2.7. Histopathology and Immunohistochemistry of Kidney. Histopathology and immunohistochemistry of kidney were performed as described previously [25]. The kidney tissue sections were kept in $4 \%$ paraformaldehyde solution and paraffin-embedded and then were cut into $3 \mu \mathrm{M}$ thickness. The renal pathological changes were examined by Periodic Acid-Schiff (PAS) staining. The expressions of TGF- $\beta 1$ $(1: 100)$ and $\alpha$-SMA $(1: 100)$ were evaluated by immunohistochemistry. The percentage of positive staining area was quantified using Image-Pro Plus 6.0 software (Media Cybernetics, Silver Spring, MD, USA).

2.8. Statistical Analysis. The Stata 10.0 statistical software (Stata) was used for all statistical analysis. Results were expressed as means \pm SEM. Differences among groups were subjected to a one-way analysis of variance (ANOVA) and $P<0.05$ was considered significantly different.

\section{Results}

3.1. Detection of Body Weight (BW), Kidney Weight/Body Weight (KW/BW), Fasting Plasma Glucose, and Insulin Levels in Mice from Different Groups. Table 1 shows the changes in BW, KW/BW, the level of glucose, and insulin level in plasma of mice after administration by gavage with or without EGCG. At baseline, the BW of db/db mice was higher than normal mice. At four and eight weeks after oral administration of EGCG, the BW of $\mathrm{db} / \mathrm{db}$ mice was still higher than normal mice, and there was no significant difference in $\mathrm{db} / \mathrm{db}$ mice of each group. However, $\mathrm{db} / \mathrm{db}$ mice treated with EGCG at 50 and $100 \mathrm{mg} / \mathrm{kg} / \mathrm{d}$ had a significantly lower KW/BW when compared to nontreated $\mathrm{db} / \mathrm{db}$ mice $(P<0.01)$. Compared with the normal group, the blood glucose level of $\mathrm{db} / \mathrm{db}$ mice was obviously higher, which persistently increased during the whole study, whereas the level of fasting plasma glucose was obviously decreased $(P<0.01)$ and the level of fasting plasma insulin was significantly increased $(P<0.01)$ in $\mathrm{db} / \mathrm{db}$ mice treated with EGCG compared to nontreated $\mathrm{db} / \mathrm{db}$ mice $(P<0.01)$ after the treatment for 4 and 8 weeks.

In addition, the area under the curve (AUC) for OGTT in $\mathrm{db} / \mathrm{db}$ mice was also higher than normal group, yet the AUC was significantly lower in $\mathrm{db} / \mathrm{db}$ mice with the treatment of EGCG than nontreated db/db mice (Figures 1(a), 1(b), 1(c), and $1(\mathrm{~d}), P<0.05)$. Furthermore, the AUC of $\mathrm{db} / \mathrm{db}$ mice treated with EGCG at $100 \mathrm{mg} / \mathrm{kg} / \mathrm{d}$ was lower in comparison with the group of $\mathrm{db} / \mathrm{db}$ mice treated with EGCG at $50 \mathrm{mg} /$ $\mathrm{kg} / \mathrm{d}$ after the oral administration for 8 weeks (Figures 1(c) and $1(\mathrm{~d}), P<0.05)$.

3.2. Changes in Urine Protein, 8-Iso-PGF2a, and Renal Homogenate Ang II after Different Treatment. Urine collection was performed $24 \mathrm{~h}$ after treatment in mice and levels of urine protein, 8-iso-PGF2a in urine, and Ang II of kidney were summarized in Table 2 . The level of $24 \mathrm{~h}$ urine protein was reduced remarkably in $\mathrm{db} / \mathrm{db}$ mice treated with EGCG compared to nontreated $\mathrm{db} / \mathrm{db}$ mice during 8-week period $(P<0.05)$. Equally, EGCG treatment significantly decreased the level of 8-iso-PGF2a in urine compared to the nontreated $\mathrm{db} / \mathrm{db}$ mice $(P<0.05)$. The significant decrease in Ang II level in kidney was also observed in $\mathrm{db} / \mathrm{db}$ mice treated with EGCG compared to nontreated $\mathrm{db} / \mathrm{db}$ mice $(P<0.05)$.

3.3. Changes in ROS, 8-OHdG, SOD, MDA, CAT, and 3Nitrotyrosine in Kidney Homogenates in Mice after Different Treatment. We also explored the changes of several parameters in kidney homogenates in mice from different groups and the results were displayed in Table 3. Compared to the normal mice, there were significant changes (significant increase or decrease) in ROS, 8-OHdG, SOD, MDA, CAT, and 3 -nitrotyrosine levels in $\mathrm{db} / \mathrm{db}$ mice $(P<0.05)$. However, EGCG treatment (both concentrations of $50 \mathrm{mg} / \mathrm{kg} / \mathrm{d}$ and $100 \mathrm{mg} / \mathrm{kg} / \mathrm{d}$ ) could obviously ameliorate the changes in the level of above parameters in $\mathrm{db} / \mathrm{db}$ mice $(P<0.05)$ during the 8-week study period. 
TABLE 1: Changes in BW, KW/BW, glucose, and insulin levels in mice after different treatment.

\begin{tabular}{|c|c|c|c|c|}
\hline & Normal & Control & EGCG A & EGCG B \\
\hline \multicolumn{5}{|l|}{$\mathrm{BW}(\mathrm{g})$} \\
\hline Baseline & $25.2 \pm 0.6$ & $33.2 \pm 0.8^{\# \#}$ & $33.4 \pm 1.0^{\# \#}$ & $33.3 \pm 1.1^{\# \#}$ \\
\hline Week 4 & $31.4 \pm 1.3$ & $39.8 \pm 1.4^{\# \#}$ & $38.9 \pm 1.9^{\# \#}$ & $39.5 \pm 1.7^{\# \#}$ \\
\hline Week 8 & $35.3 \pm 1.1$ & $45.6 \pm 1.2^{\# \#}$ & $44.2 \pm 1.8^{\# \#}$ & $44.3 \pm 3.1^{\# \#}$ \\
\hline \multicolumn{5}{|c|}{ KW/BW (mg/g) } \\
\hline Baseline & $3.5 \pm 0.4$ & $6.5 \pm 0.2^{\# \#}$ & $6.3 \pm 0.5^{\# \#}$ & $6.4 \pm 0.4^{\# \#}$ \\
\hline Week 4 & $3.6 \pm 0.4$ & $8.1 \pm 0.3^{\# \#}$ & $7.1 \pm 0.8^{\# \# * *}$ & $7.3 \pm 0.1^{\# * * *}$ \\
\hline Week 8 & $4.0 \pm 0.6$ & $8.4 \pm 0.1^{\# \#}$ & $7.4 \pm 0.2^{\# \# * *}$ & $7.5 \pm 0.1^{\# \# * *}$ \\
\hline \multicolumn{5}{|c|}{ Glucose $(\mathrm{mmol} / \mathrm{L})$} \\
\hline Baseline & $4.9 \pm 0.3$ & $11.5 \pm 0.9^{\# \#}$ & $11.3 \pm 1.1^{\# \#}$ & $11.5 \pm 1.1^{\# \#}$ \\
\hline Week 4 & $4.5 \pm 0.9$ & $15.1 \pm 0.5^{\# \#}$ & $12.8 \pm 1.0^{\# \# * * *}$ & $12.1 \pm 0.6^{\# \# * *}$ \\
\hline Week 8 & $4.7 \pm 0.8$ & $17.2 \pm 0.8^{\# \#}$ & $14.4 \pm 1.0^{\# \# * *}$ & $14.2 \pm 0.7^{\# \# * *}$ \\
\hline \multicolumn{5}{|c|}{ Insulin $(\mathrm{ng} / \mathrm{mL})$} \\
\hline Baseline & $3.3 \pm 1.3$ & $5.6 \pm 1.4^{\#}$ & $5.4 \pm 1.1^{\#}$ & $5.7 \pm 0.8^{\#}$ \\
\hline Week 4 & $3.2 \pm 0.7$ & $5.5 \pm 1.1^{\#}$ & $7.8 \pm 0.8^{\# *}$ & $8.0 \pm 0.9^{\# \# * *}$ \\
\hline Week 8 & $3.5 \pm 1.1$ & $5.2 \pm 1.7^{\#}$ & $11.2 \pm 2.2^{\# \# * *}$ & $12.4 \pm 1.6^{\# \# * *}$ \\
\hline
\end{tabular}

Note: normal, C57BLKS/J normal nontreated mice; control, C57BLKS/J db/db nontreated mice; EGCG A, db/db mice treated with EGCG of 50 mg/kg/d; EGCG B, db/db mice treated with EGCG of $100 \mathrm{mg} / \mathrm{kg} / \mathrm{d}$; BW, body weight; KW/BW, kidney weight/body weight; glucose, fasting plasma glucose; insulin, fasting plasma insulin; ${ }^{\#} P<0.05$ and ${ }^{\# \#} P<0.01$ versus normal; ${ }^{*} P<0.05$ and ${ }^{* *} P<0.01$ versus control; values are means \pm SEM. At baseline and at week $4, n=16$ in each group; at week $8, n=8$ in each group.

TABLE 2: Changes of 24-hour urinary protein, urinary 8-iso-PGF2a, and renal Ang II levels in urine $24 \mathrm{~h}$ after different treatment.

\begin{tabular}{|c|c|c|c|c|}
\hline & Normal & Control & EGCG A & EGCG B \\
\hline \multicolumn{5}{|c|}{ 24-hour urinary protein $(\mathrm{mg})$} \\
\hline Baseline & $1.2 \pm 0.3$ & $5.8 \pm 0.6^{\# \#}$ & $5.9 \pm 0.9^{\# \#}$ & $5.7 \pm 1.1^{\# \#}$ \\
\hline Week 4 & $1.1 \pm 0.7$ & $7.5 \pm 0.2^{\# \#}$ & $6.7 \pm 0.1^{\# \# * *}$ & $6.7 \pm 0.5^{\# \# *}$ \\
\hline Week 8 & $1.3 \pm 0.5$ & $11.9 \pm 1.3^{\# \#}$ & $8.8 \pm 1.0^{\# \# *}$ & $8.6 \pm 1.1^{\# \# *}$ \\
\hline \multicolumn{5}{|c|}{ Urinary 8-iso-PGF2a (ng/d) } \\
\hline Baseline & $38.5 \pm 5.3$ & $84.6 \pm 8.5^{\# \#}$ & $87.2 \pm 11.3^{\# \#}$ & $86.8 \pm 12.1^{\# \#}$ \\
\hline Week 4 & $39.8 \pm 3.6$ & $150.4 \pm 11.9^{\# \#}$ & $107.3 \pm 12.1^{\# \# * *}$ & $110.6 \pm 9.2^{\# \# * *}$ \\
\hline Week 8 & $38.7 \pm 4.4$ & $176.8 \pm 10.1^{\# \#}$ & $138.5 \pm 8.3^{\# \# * *}$ & $126.7 \pm 9.5^{\# \# * *}$ \\
\hline \multicolumn{5}{|c|}{ Renal Ang II (ng/L) } \\
\hline Baseline & $177.6 \pm 20.2$ & $238.3 \pm 14.2^{\# \#}$ & $240.5 \pm 19.8^{\# \#}$ & $238.9 \pm 16.6^{\# \#}$ \\
\hline Week 4 & $182.4 \pm 12.1$ & $346.2 \pm 22.7^{\# \#}$ & $297.5 \pm 15.5^{\# \# *}$ & $308.9 \pm 7.3^{\# \# *}$ \\
\hline Week 8 & $191.3 \pm 23.9$ & $405.8 \pm 7.2^{\# \#}$ & $367.4 \pm 5.4^{\# \# * *}$ & $383.7 \pm 9.6^{\# \# *}$ \\
\hline
\end{tabular}

Note: normal, C57BLKS/J normal nontreated mice; control, C57BLKS/J db/db nontreated mice; EGCG A, db/db mice treated with EGCG of 50 mg/kg/d; EGCG B, db/db mice treated with EGCG of $100 \mathrm{mg} / \mathrm{kg} / \mathrm{d}$; urinary 8-iso-PGF2a, urinary 8-iso-prostaglandin F2 $\alpha$; Ang II: the renal angiotensin II concentration; ${ }^{\# \#} P<0.01$ versus normal; ${ }^{*} P<0.05$ and ${ }^{* *} P<0.01$ versus control; values are means \pm SEM. At baseline and at week $4, n=16$ in each group; at week 8 , $n=8$ in each group.

3.4. Changes in Expression of AT-1R, TGF- $\beta 1, p 22-p h o x$, and p47-phox in Kidney Tissue in Mice after Different Treatment. As shown in Table 2, the renal Ang II level was increased in mice after treatment with EGCG. Moreover, we also explored the effects of EGCG on AT-1R, which is the receptor of Ang II. Following our results, the level of AT-1R was significantly downregulated in mice after oral administration of EGCG for 4 and 8 weeks (Figures 2(a) and 2(c), $P<0.01$ ). Therefore, EGCG may play a role similar to Ang II type 1 receptor blocker. Likewise, the protein expression level of TGF- $\beta 1$ in renal tissue was also obviously downregulated after treatment of EGCG (Figures 2(a) and 2(b), $P<0.01$ ).
Hyperglycemia-induced oxidative stress plays an important role in the procession and development of $\mathrm{DKD}$, which was confirmed by Western blot analysis in our study. Compared with the normal group, p22-phox and p47-phox (both were NADPH oxidase subunits) were upregulated in nontreated $\mathrm{db} / \mathrm{db}$ mice, while EGCG treatment significantly reduced the protein expression of p22-phox and p47-phox in $\mathrm{db} / \mathrm{db}$ mice (Figures 3(a), 3(b), and 3(c), $P<0.05$ ).

3.5. Changes in the Expression of MAPK Signaling Pathway. Given that the oxidative stress may activate the MAPK cascade, we explored the changes in expression of $\mathrm{p}$-ERK1/2 and 


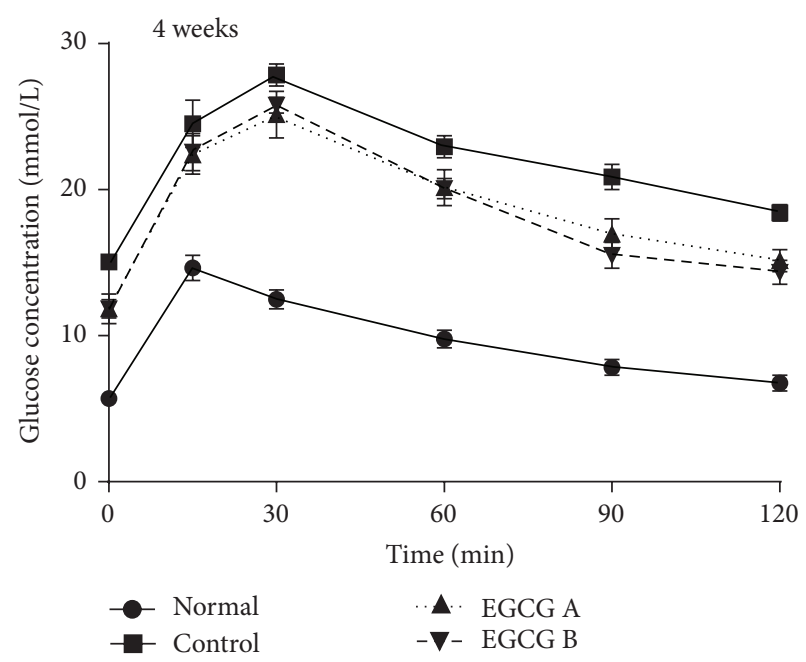

(a)

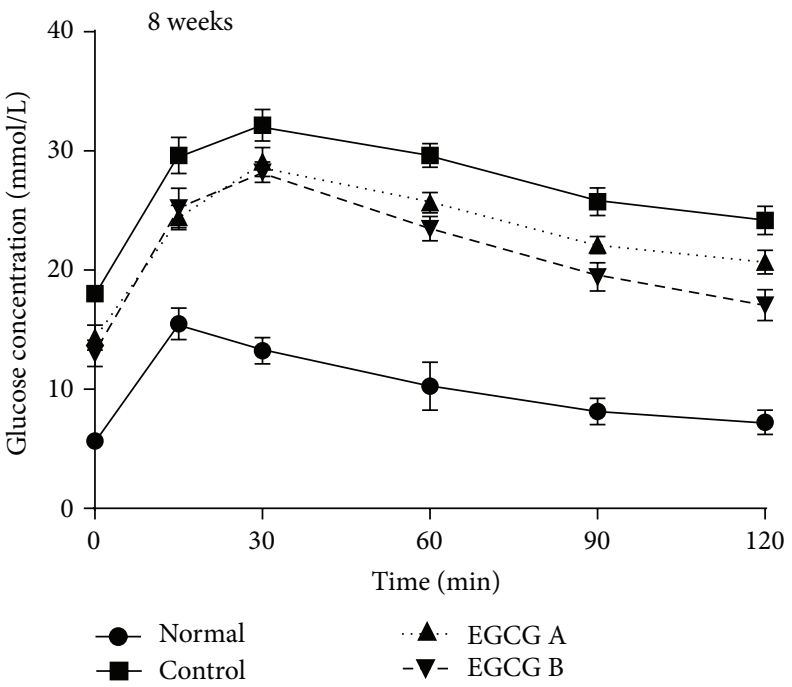

(c)

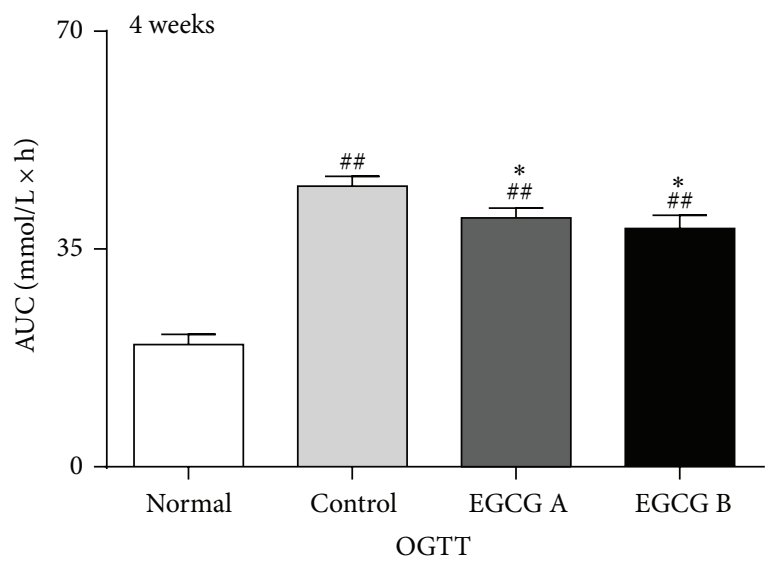

(b)



(d)

FIGURE 1: Glucose metabolic profile in $\mathrm{db} / \mathrm{db}$ mice versus control mice. Diabetic $\mathrm{db} / \mathrm{db}$ mice were treated with or without EGCG for 4 or 8 weeks, and OGTT (glucose, $1 \mathrm{~g} / \mathrm{kg}$ ) were performed. Glucose concentrations (a and c) and the AUC of OGTT (b and d) were shown. Normal: nontreated C57BL mice; control: C57BLKS/J db/db nontreated mice; EGCG A, db/db mice treated with EGCG of 50 mg/kg/d; EGCG B, $\mathrm{db} / \mathrm{db}$ mice treated with EGCG of $100 \mathrm{mg} / \mathrm{kg} / \mathrm{d}$; values are means \pm SEM. ${ }^{\# \#} P<0.01$ versus normal; ${ }^{*} P<0.05$ and ${ }^{* *} P<0.01$ versus control; ${ }^{\&} P<0.05$ versus EGCG A. At week $4, n=16$ in each group; at week $8, n=8$ in each group.

p-p38 MAPK (both are important members of MAPK family) in kidney tissue in mice after EGCG treatment (Figure 4(a)). In this study, we found that the protein expressions of $\mathrm{p}$ ERK1/2 and p-p38 MAPK were obviously increased in nontreated $\mathrm{db} / \mathrm{db}$ mice compared to those in the kidney tissue in normal mice, and both of them were significantly reduced in mice after treatment of EGCG (Figures 4(b) and 4(c), $P<$ 0.05).

3.6. EGCG Ameliorated Renal Damage and Fibrosis in $d b / d b$ Mice. The renoprotective effects of EGCG in ameliorating renal damage and fibrosis were investigated by PAS and immunohistochemical staining (Figures 5(a), 5(b), and 5(c)). Compared to the normal mice, there was an increase of glomerular volume and mesangial matrix expansion, and
EGCG treatment could attenuate these histological changes in $\mathrm{db} / \mathrm{db}$ mice confirmed by PAS staining (Figure 5(a)). Results from statistical analysis indicated that EGCG could significantly reduce mesangial matrix index in $\mathrm{db} / \mathrm{db}$ mice (Figure 5(d), $P<0.05)$. Additionally, the expression levels of TGF- $\beta 1$ and $\alpha$-SMA, which were associated with the development of fibrosis, were significantly downregulated after EGCG treatment in $\mathrm{db} / \mathrm{db}$ mice compared to those in nontreated mice (Figures 5(b), 5(c), and 5(e), $P<0.05$ ).

3.7. Effects of EGCG on Ang II Induced Renal Kidney Injury in HK-2 Cells. To explore the underlying mechanism of EGCG in renoprotection, we investigated the role of EGCG in Ang II mediated renal injury pathway in HK-2 cells. Following our results in Figure 6, after intervention with EGCG, the 


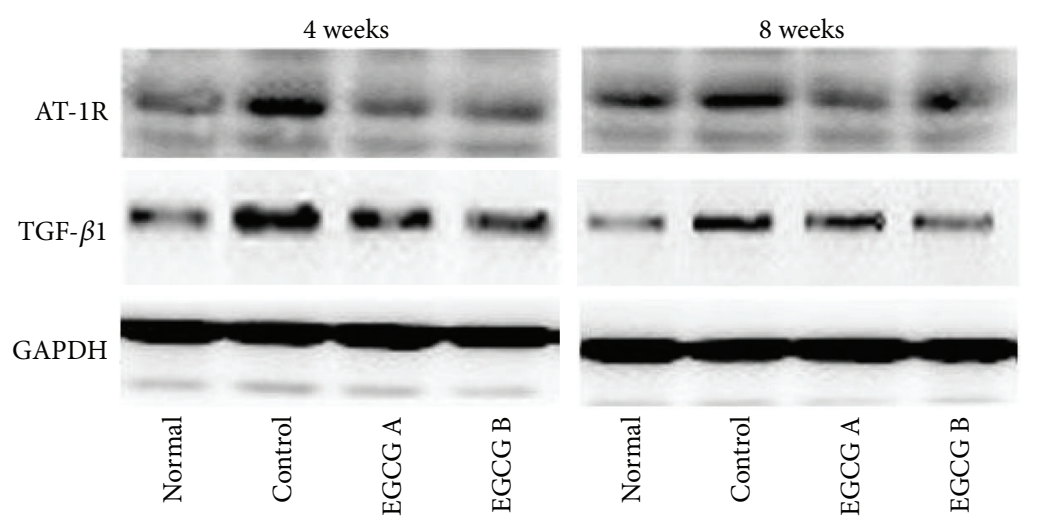

(a)

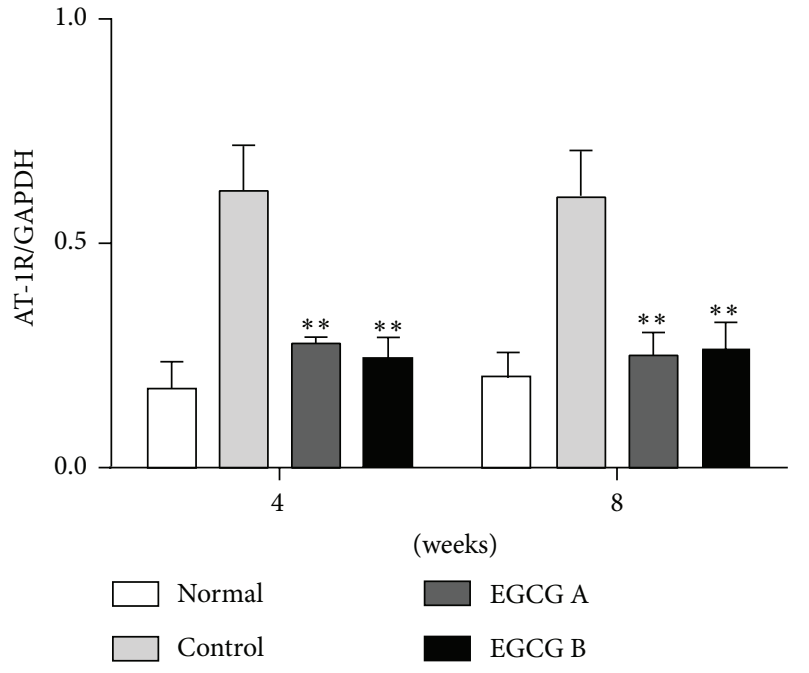

(b)

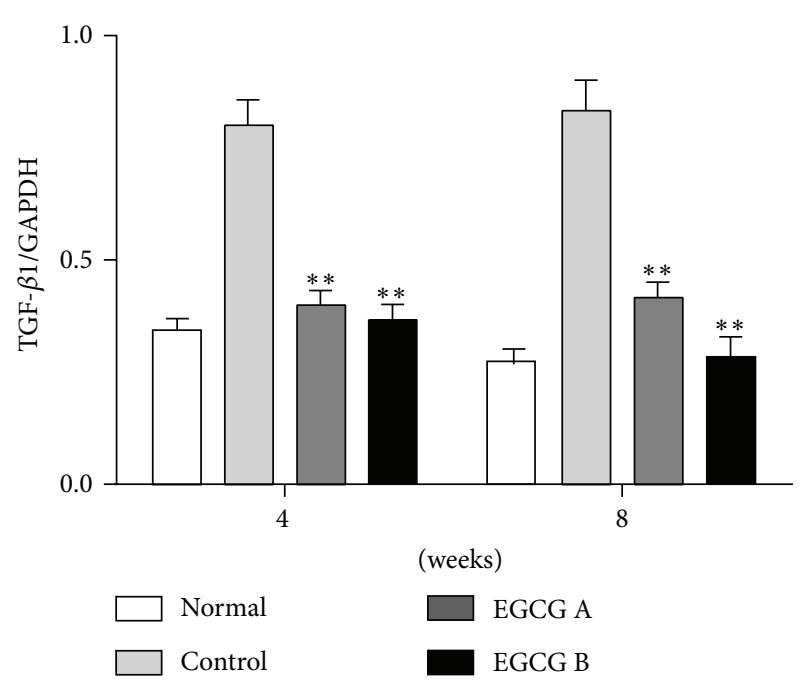

(c)

FIGURE 2: The protein expressions of AT-1R (b) and TGF- $\beta 1$ (c) in renal tissue of mice detected by Western blot. Normal: nontreated C57BL mice; control: C57BLKS/J db/db nontreated mice; EGCG A, db/db mice treated with EGCG of $50 \mathrm{mg} / \mathrm{kg} / \mathrm{d}$; EGCG B, db/db mice treated with EGCG of $100 \mathrm{mg} / \mathrm{kg} / \mathrm{d}$; values are means \pm SEM. ${ }^{* *} P<0.01$ versus control. At both week 4 and week $8, n=8$ in each group.

increased expression of NOX-1 (Figures 6(a) and 6(b)), NOX4 (Figures 6(a) and 6(b)), p22-phox (Figures 6(a) and 6(c)), p47-phox (Figures 6(a) and 6(c)), p-ERK1/2 (Figures 6(a) and 6(d)), p-P38 MAPK (Figures 6(a) and 6(e)), TGF- $\beta 1$ (Figures 6(a) and 6(f)), and $\alpha$-SMA (Figures 6(a) and 6(f)) induced by Ang II was significantly downregulated $(P<0.05)$. We also explored the role of PD98059 and SB202190 in Ang II mediated renal fibrosis. Based on our results, PD98059 and SB202190 can significantly decrease the expression of pERK1/2 (Figures 7(a) and 7(b)), p-P38 MAPK (Figures 7(a) and $7(\mathrm{c})$ ), TGF- $\beta 1$ (Figures 7(a) and 7(d)), and $\alpha$-SMA (Figures 7(a) and 7(e)) even in the presence of Ang II $(P<0.05)$. Hence, EGCG is supposed to play a role in Ang II induced renal injury similar to PD98059 and SB202190.

\section{Discussion}

In this study, we founded that EGCG treatment at 50 or $100 \mathrm{mg} / \mathrm{kg} / \mathrm{d}$ for 4 and 8 weeks could decrease the level of plasma glucose and also increase the level of plasma insulin in $\mathrm{db} / \mathrm{db}$ mice. Moreover, $24 \mathrm{~h}$ urinary protein, 8 -iso-PGF2a, and renal Ang II levels were also reduced by EGCG treatment. EGCG could also change the level of several parameters in renal homogenate including ROS, 8-OHdG, SOD, MDA, $\mathrm{CAT}$, and 3-nitrotyrosine in $\mathrm{db} / \mathrm{db}$ mice. In addition, EGCG treatment at dose of 50 and $100 \mathrm{mg} / \mathrm{kg} / \mathrm{d}$ could also downregulate the expression of several factors involved in the signaling pathways activated by ROS production, including AT1R, p22-phox, p47-phox, p-ERK1/2, p-p38 MAPK, TGF- $\beta 1$, and $\alpha$-SMA. Meanwhile, the pathological changes in diabetic $\mathrm{db} / \mathrm{db}$ mice such as renal injury and fibrosis could be also ameliorated after EGCG treatment. Thus, we supposed that EGCG, a constituent of green tea, had beneficial effects on the kidney of diabetic $\mathrm{db} / \mathrm{db}$ mice.

To date, numerous studies have suggested that oxidative stress can lead to kidney injury and accelerate the procession and development of DKD [2,4-6]. Oxidative stress of DKD is mainly derived from hyperglycemia. Hence, controlling hyperglycemia is supposed to be an effective approach to slow the procession and development of DKD. Previous studies 


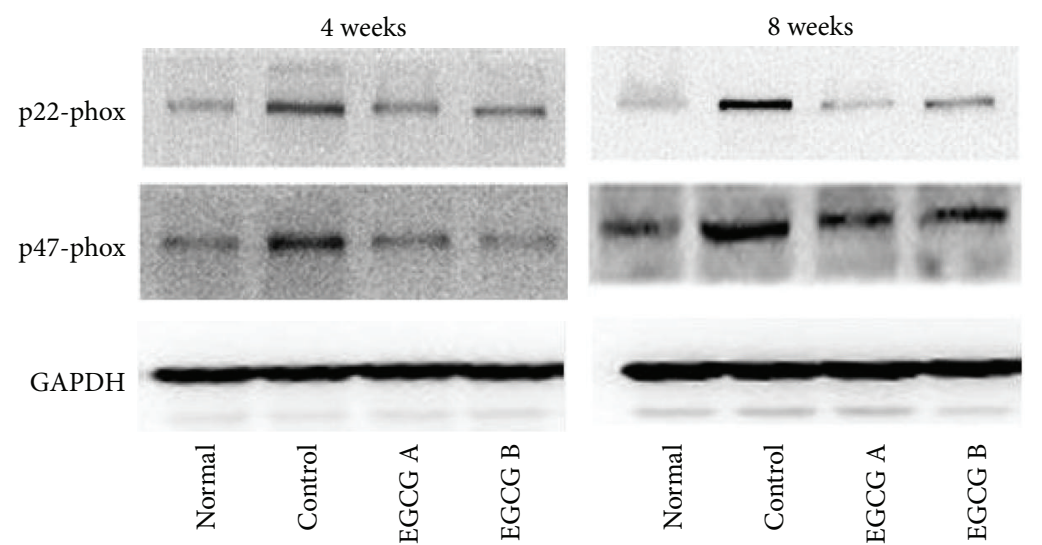

(a)

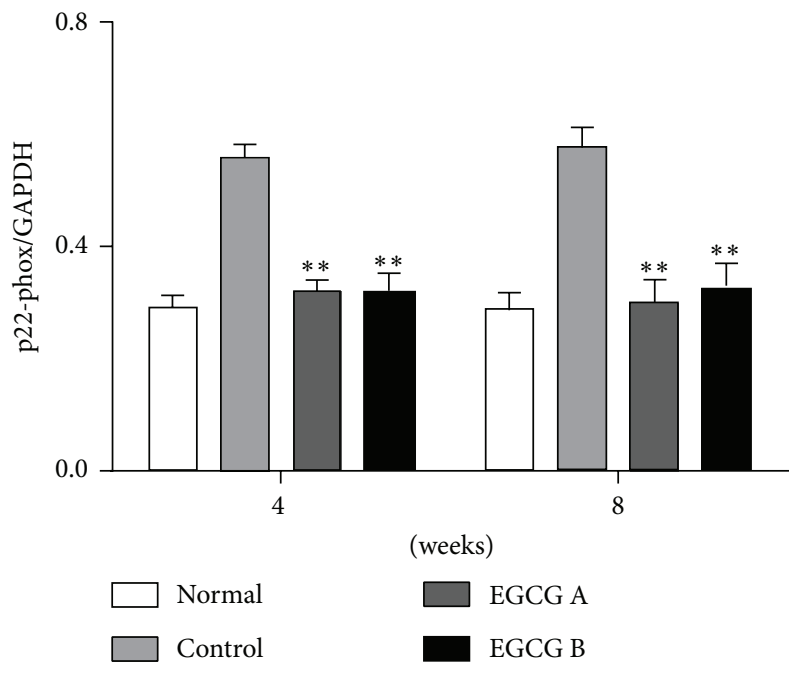

(b)

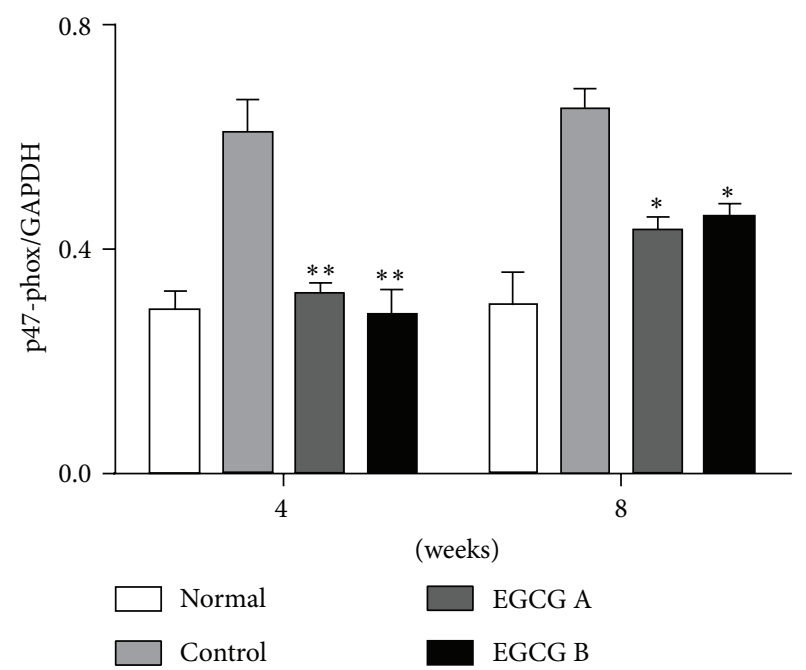

(c)

Figure 3: The protein expressions of p22-phox (b) and p47-phox (c) in renal tissue of mice detected by Western blot. Normal: nontreated C57BL mice; control: C57BLKS/J db/db nontreated mice; EGCG A, db/db mice treated with EGCG of 50 mg/kg/d; EGCG B, db/db mice treated with EGCG of $100 \mathrm{mg} / \mathrm{kg} / \mathrm{d}$; values are means \pm SEM. ${ }^{*} P<0.05$ and ${ }^{* *} P<0.01$ versus control. At both week 4 and week $8, n=8$ in each group.

have shown that EGCG has antihyperglycemia effect [16, $19,26]$. However, results from our study demonstrated that EGCG plays a role in regulating glycol metabolism. The level of fasting plasma glucose was decreased and the level of fasting plasma insulin was increased in $\mathrm{db} / \mathrm{db}$ mice after treatment of EGCG. Furthermore, the AUC was significantly lower in $\mathrm{db} / \mathrm{db}$ mice treated with EGCG compared to nontreated $\mathrm{db} / \mathrm{db}$ mice. Interestingly, all these beneficial effects of EGCG were not obviously dose-dependent. On the other hand, there was no significant difference between the doses of $50 \mathrm{mg} / \mathrm{kg} / \mathrm{d}$ and $100 \mathrm{mg} / \mathrm{kg} / \mathrm{d}$.

ROS production is a major process of oxidative stress, which has been shown to participate in DKD through various mechanisms, such as stimulating the expression of Ang II, inducing the production of TGF- $\beta 1$ and $\alpha$-SMA, and activating the MAPK cascade [7-11].

DKD is once considered to be caused by combined effects of hemodynamic changes and metabolic factors. This theory cannot clearly elucidate the pathogenesis of $\mathrm{DKD}$, while hemodynamic factors are supposed to play an important role in the development of DKD $[27,28]$ learning from it. As described previously, the hemodynamic changes in kidney are related to the progression of DKD, and ROS takes part in these changes of renal hemodynamics in diabetic conditions, which stimulates the expression of renin angiotensin system (RAS) $[27,29,30]$. ROS-induced activation of Ang II, a crucial component of RAS, is able to increase intraglomerular pressure and activate the intracellular second messengers, which eventually results in the upregulation of urinary protein and renal fibrosis [31]. In addition, the increased level of Ang II accelerates the production of ROS [7]. AT-1R, the important receptor of Ang II, has been shown to play a significant role in increasing the urinary protein level [32]. It has been reported that, in diabetic conditions, there is a vicious circle: ROS-angiotensinogen-Ang II-AT-1R-ROS [33]. Moreover, studies have confirmed that AT-1R blocker remarkably alleviated the level of urinary protein of DKD patients [33]. Based on the results from our study, EGCG not only obviously 


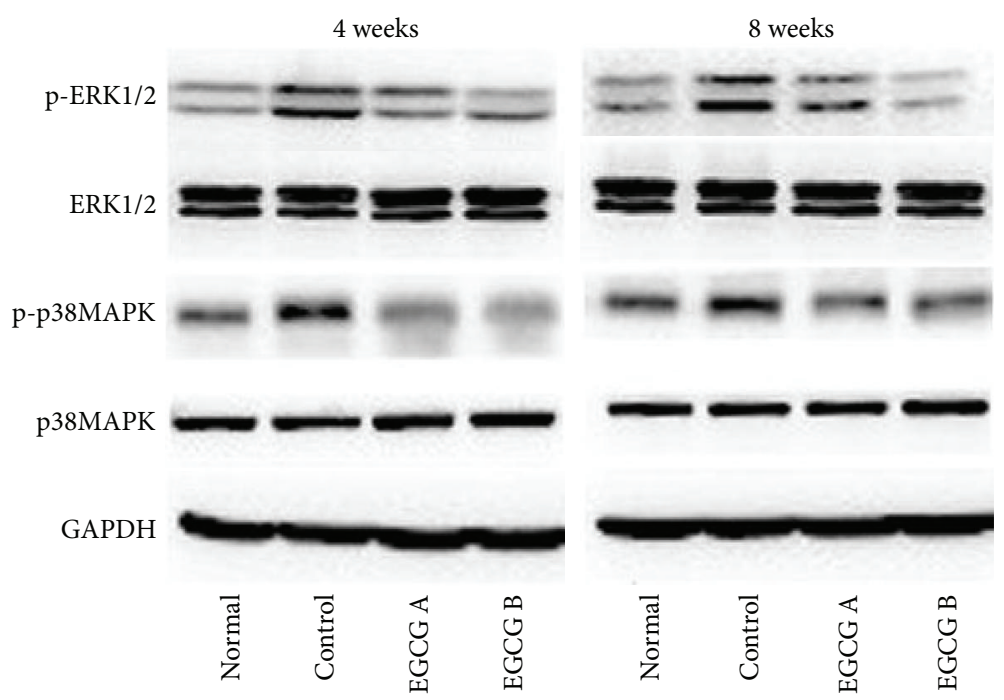

(a)

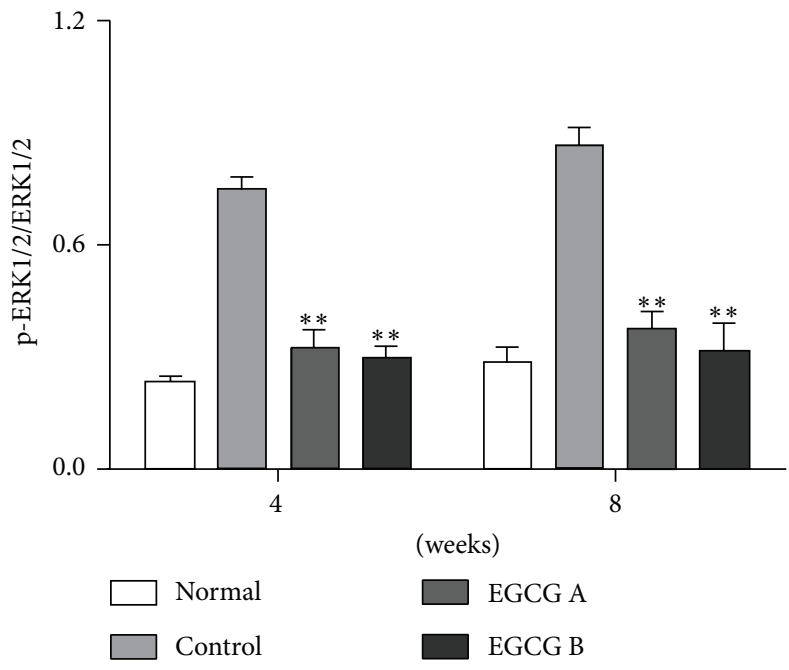

(b)

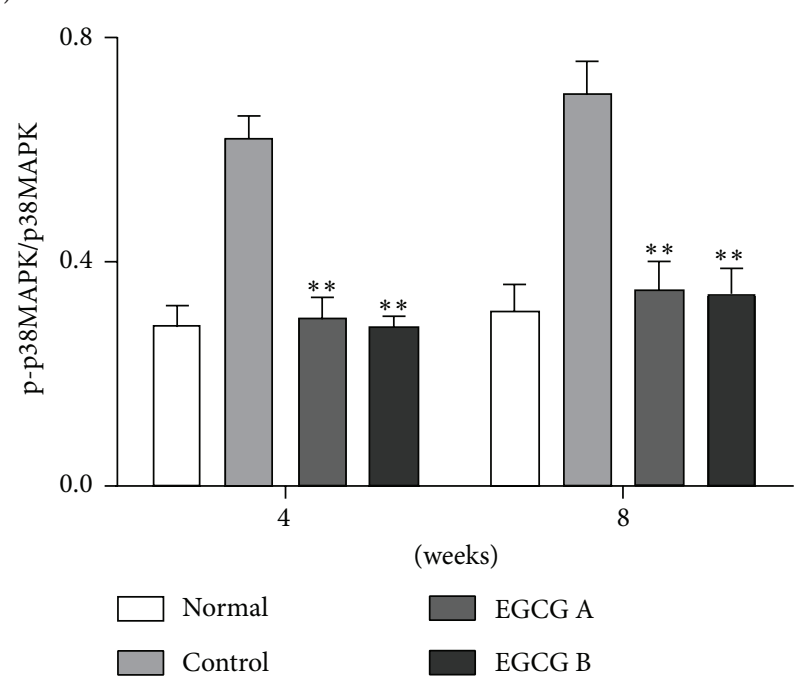

(c)

FIGURE 4: The protein expression of p-ERK1/2 (b) and p-P38 MAPK (c) in renal tissue of mice detected by Western blot. Normal: nontreated C57BL mice; control: C57BLKS/J db/db nontreated mice; EGCG A, db/db mice treated with EGCG of $50 \mathrm{mg} / \mathrm{kg} / \mathrm{d}$; EGCG B, db/db mice treated with EGCG of $100 \mathrm{mg} / \mathrm{kg} / \mathrm{d}$; values are means \pm SEM. ${ }^{* *} P<0.01$ versus control. At both week 4 and week $8, n=8$ in each group.

inhibited the level of ROS-induced Ang II expression in the renal homogenate but also significantly suppressed the protein expression of AT-1R. The effect of EGCG on AT-1R has been reported in only two studies. One study indicated that EGCG significantly reduced the expression of AT-1R mRNA in the liver of SHRSP-ZF rats [34], and the other demonstrated that EGCG could restore AT-1R mRNA expression to normal level which was decreased by Ang II stimulation in rat cardiac fibroblasts. In this study, it was the first time to show that EGCG decreased the protein expression of AT$1 \mathrm{R}$ in renal tissues of DKD [35]. Hence, EGCG may function as an AT-1R blocker. Further study should be performed to compare the effects of EGCG with olmesartan (AT-1R specific blocker) on kidney pathological changes in $\mathrm{db} / \mathrm{db}$ mice.

Oxidative stress is considered the major culprit in kidney tissues. NADPH oxidase is abundantly distributed in mesangial cells, and renal tubular cells are also the targeted cells of ROS. ROS can induce the apoptosis of both mesangial cells and tubular cells in kidney, leading to pathological changes, eventually causing glomerular sclerosis and tubuleinterstitial fibrosis. Studies have demonstrated that a major source for generation of ROS is NADPH oxidase in highglucose conditions $[5,6,13-15]$. It has been reported that NADPH oxidase inhibitor can effectively inhibit the generation of ROS and delay the progression of DKD in the type 2 diabetic rat model [13]. In this study, our data demonstrated that the protein expression levels of p22-phox and p47-phox were significantly decreased in $\mathrm{db} / \mathrm{db}$ mice after EGCG treatment. Similarly, the pathological changes in kidney were alleviated in mice after the oral administration with EGCG. Furthermore, the levels of $24 \mathrm{~h}$ urinary protein and 8-iso-PGF2a and renal Ang II were also reduced with the treatment of 

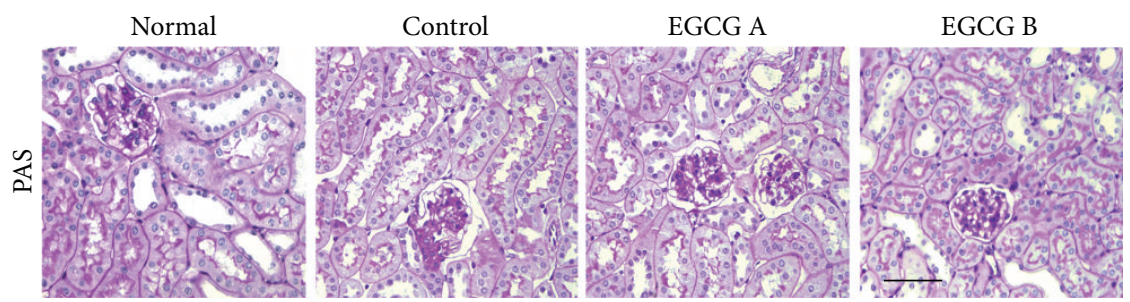

(a)
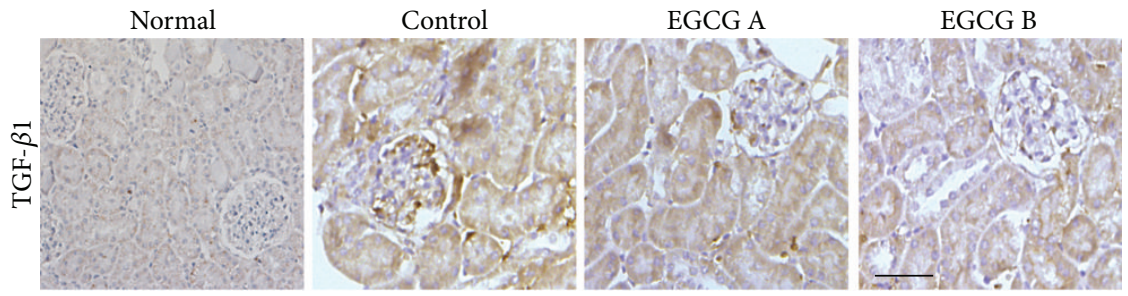

(b)
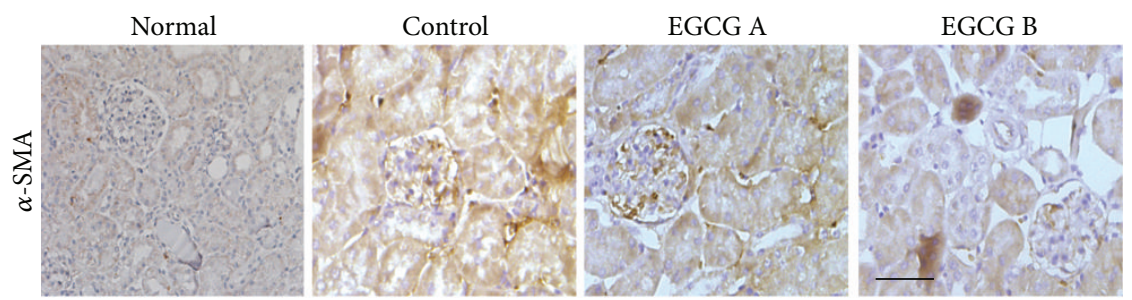

(c)
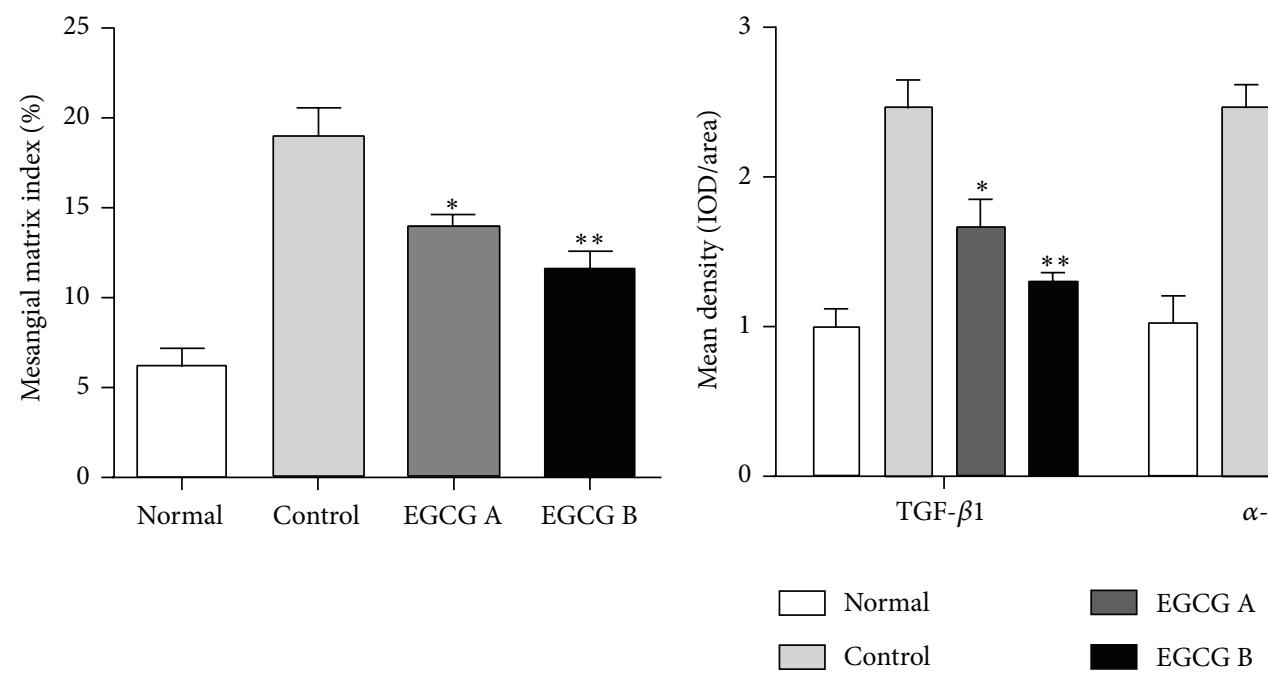

(d)

(e)

FIGURE 5: Effect of EGCG on renal pathological changes and fibrosis. Renal pathological changes were examined by PAS staining (a and d). The protein expression levels of TGF- $\beta 1$ and $\alpha$-SMA were evaluated by immunohistochemistry (b, c, and e). Scale bar: $50 \mu \mathrm{m} ; n=8$ in each group. Normal: nontreated C57BL mice; control: C57BLKS/J db/db nontreated mice; EGCG A, db/db mice treated with EGCG of 50 mg/kg/d; EGCG B, db/db mice treated with EGCG of $100 \mathrm{mg} / \mathrm{kg} / \mathrm{d}$; values are means \pm SEM. ${ }^{*} P<0.05$ and ${ }^{* *} P<0.01$ versus control.

EGCG. Considering these results, EGCG exerts antioxidant effect in DKD of $\mathrm{db} / \mathrm{db}$ mice. However, some other studies show that EGCG has the ability to exert prooxidative activities [20, 21]. These discrepancies may be caused by the different mechanism of EGCG involved in different diseases. It is well known that molecules play different roles, even totally opposite roles, in different cells or tissues. EGCG may have prooxidative activities in other diseases, while it shows an antioxidative effect in renal injury.

Oxidative stress-induced inflammatory response is a major pathomechanism of DKD. Moreover, the increase of inflammatory cytokine levels under high glucose conditions in return could induce a further increase of oxidative stress forming a vicious cycle [36]. It has been reported that 


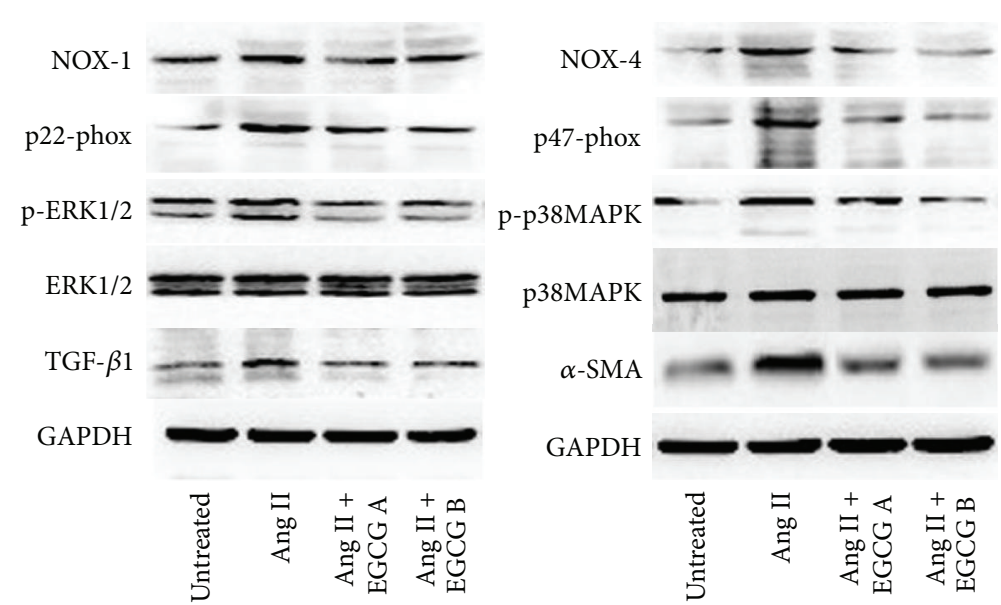

(a)

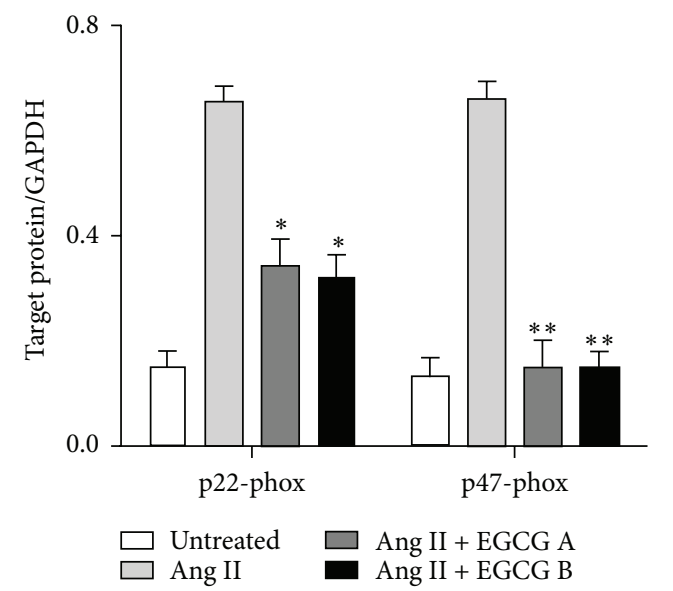

(c)

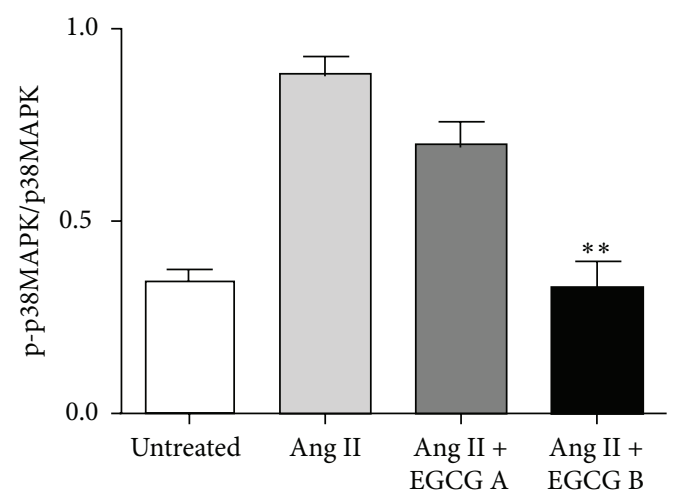

(e)

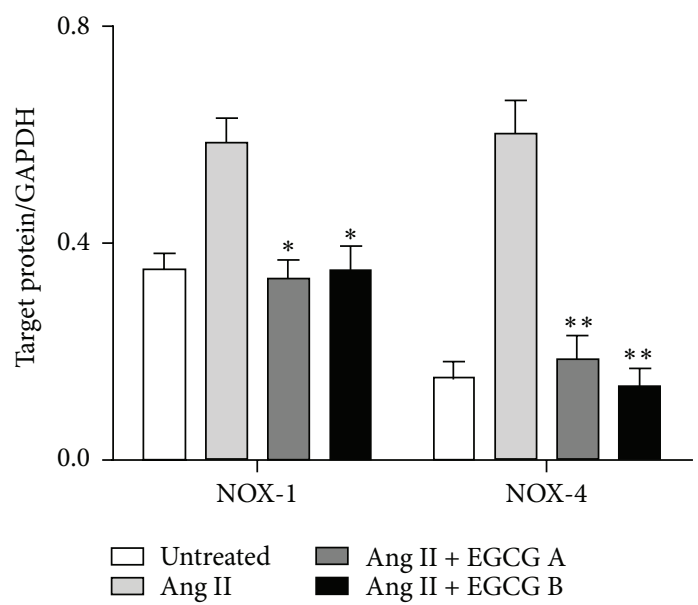

(b)

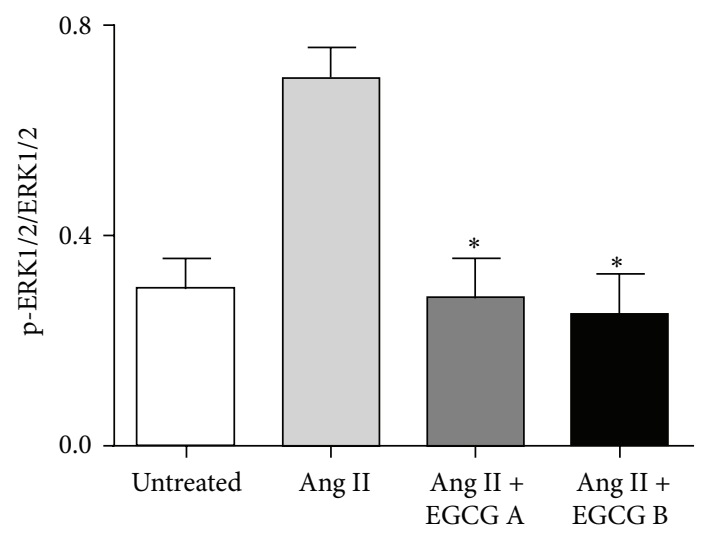

(d)

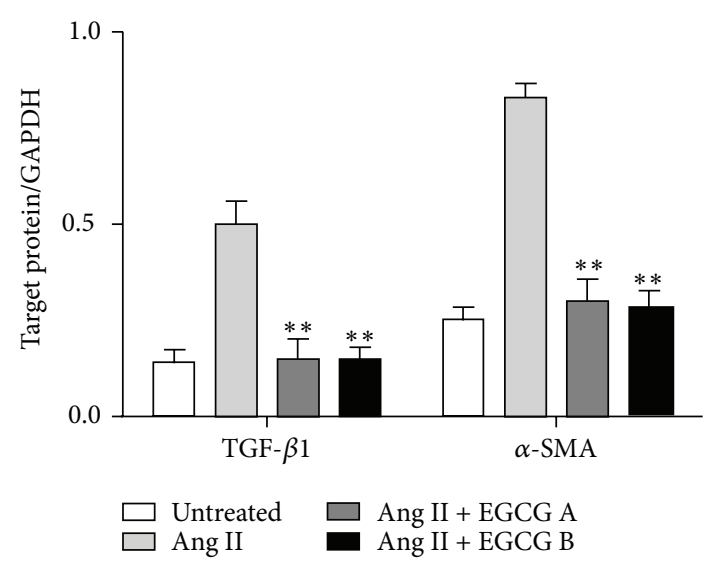

(f)

FIGURE 6: The protein expression of NOX-1 and NOX-4 (b), p22-phox and p47-phox (c), p-ERK1/2 (d), p-P38 MAPK (e), and TGF- $\beta 1$ and $\alpha$-SMA (f) of HK-2 cell after exposure to Ang II and EGCG detected by Western blot analyses. HK-2 cells were pretreated with 15 or $30 \mu \mathrm{M}$ of EGCG for $6 \mathrm{~h}$ and then stimulated with Ang II $(1 \mu \mathrm{M})$ for 24 hours. Values are means \pm SEM. ${ }^{*} P<0.05$ and ${ }^{* *} P<0.01$ versus control.

oxidative stress is a major contributor to the increase of TGF- $\beta 1$ and $\alpha$-SMA in DKD through direct or indirect ways $[9,36]$. Both TGF- $\beta 1$ and $\alpha$-SMA are hypertrophic and fibrogenic cytokines which play a major role in glomerular hypertrophy and mesangial matrix expansion and finally lead to end-stage renal disease [36]. In addition, NADPH oxidase inhibitor effectively decreases TGF- $\beta 1$ and $\alpha$-SMA levels [37]. Furthermore, MAPK signaling pathways can be activated by ROS and participate in regulation of the inflammatory cytokines and processes [11]. It has been reported that ERK1/2 


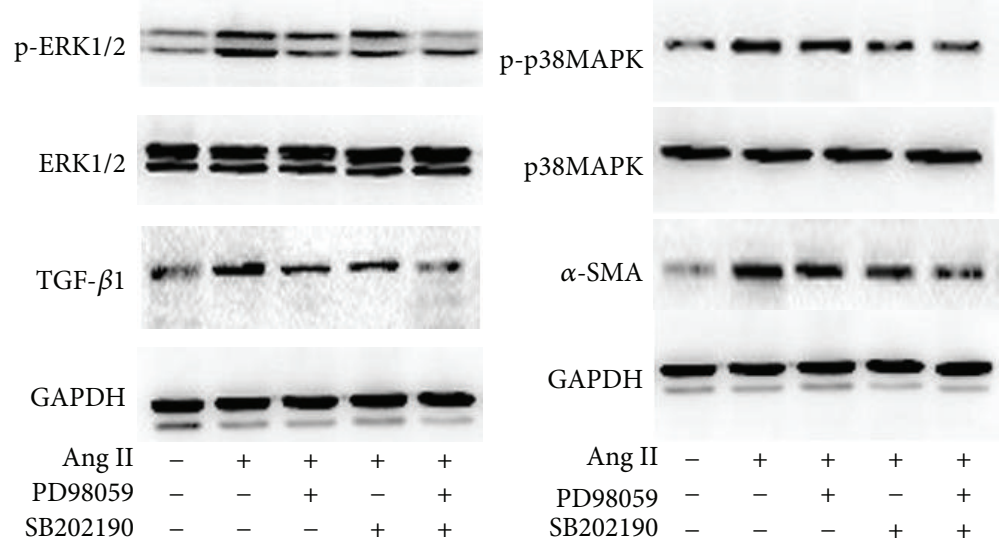

(a)

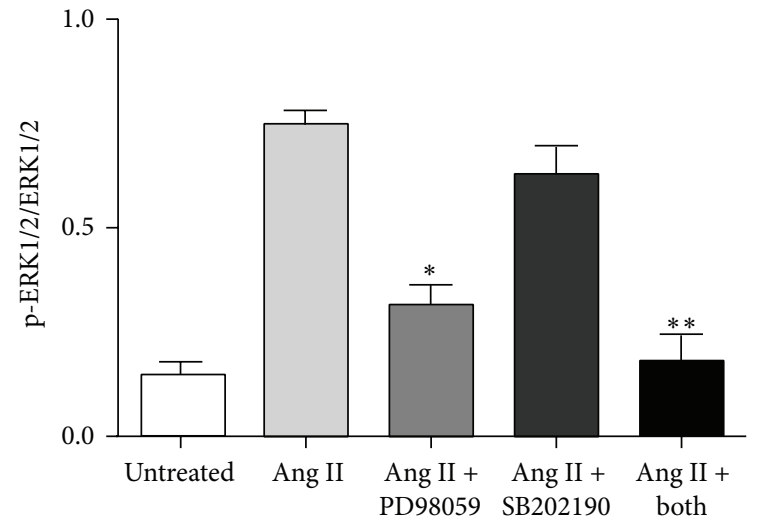

(b)

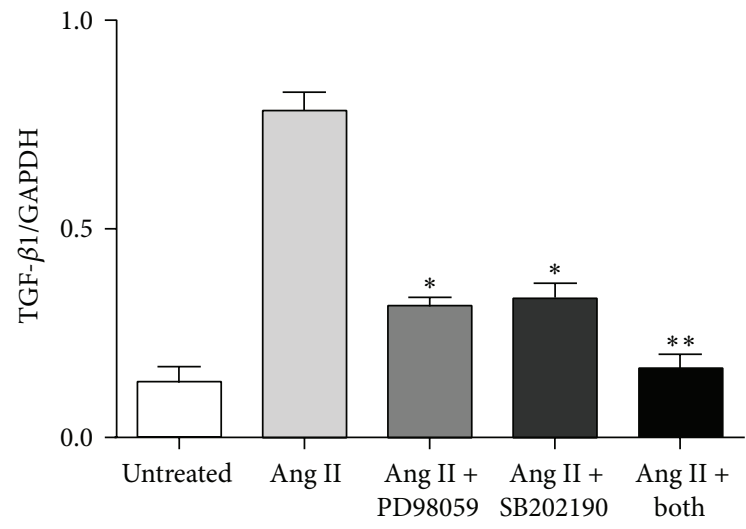

(d)

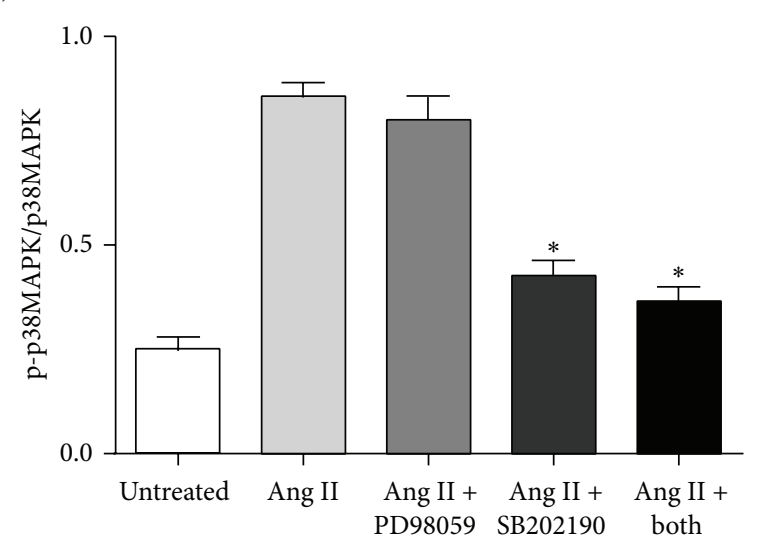

(c)

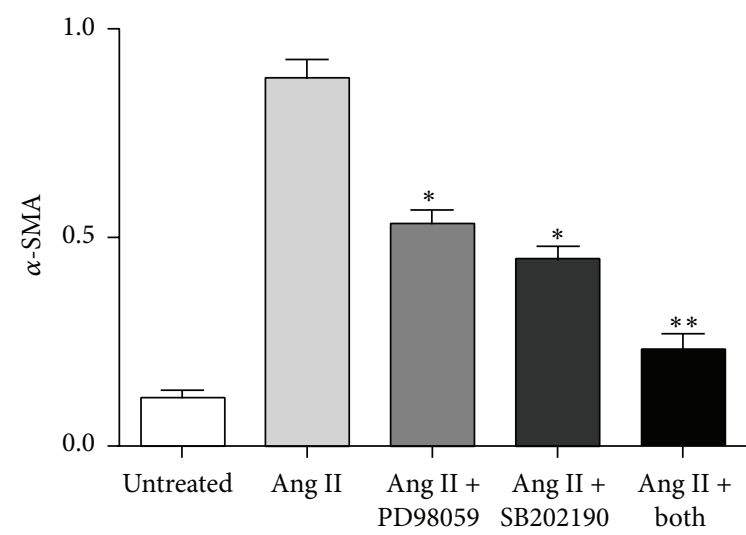

(e)

FIgure 7: The protein expression of p-ERK1/2 (b), p-P38 MAPK (c), TGF- $\beta 1$ (d), and $\alpha$-SMA (e) of HK-2 cell after exposure to Ang II, PD98059, and SB202190. HK-2 cells were pretreated with PD98059 (ERK1/2 inhibitor) and/or SB202190 (p38 MAPK inhibitor) (all 10 mM) for $6 \mathrm{~h}$ and then stimulated with Ang II $(1 \mu \mathrm{M})$ for 24 hours. Values are means \pm SEM. ${ }^{*} P<0.05$ and ${ }^{* *} P<0.01$ versus control.

and p38 MAPK, members of MAPK family, are crucial to mediate cellular responses such as inducing the proliferation, differentiation, and apoptosis of kidney cells and activating inflammatory processes $[11,33]$. Therefore, TGF- $\beta 1, \alpha$-SMA, and MAPK signaling pathways which are stimulated by ROS are closely associated with the development of DKD. In this study, the $\mathrm{db} / \mathrm{db}$ nontreated mice displayed obviously increased protein expression levels of p-ERK1/2 and p-p38 MAPK confirmed by Western blot and levels of TGF- $\beta 1$ and $\alpha$-SMA determined by immunohistochemistry compared to normal group. On the other hand, the increase levels of TGF- $\beta 1, \alpha$-SMA, p-ERK1/2, and p-p38 MAPK were inhibited by EGCG in diabetic conditions. Furthermore, in order to further explore the underlying molecular mechanism of 
TABLE 3: Changes in ROS, 8-OHdG, SOD, MDA, CAT, and 3-nitrotyrosine in kidney homogenates in mice after different treatment.

\begin{tabular}{|c|c|c|c|c|}
\hline & Normal & Control & EGCG A & EGCG B \\
\hline \multicolumn{5}{|c|}{$\mathrm{ROS}(\mathrm{U} / \mathrm{mL})$} \\
\hline Baseline & $201.4 \pm 17.5$ & $279.1 \pm 17.8^{\# \#}$ & $280.4 \pm 20.7^{\# \#}$ & $277.6 \pm 23.2^{\# \#}$ \\
\hline Week 4 & $203.9 \pm 10.7$ & $372.2 \pm 20.2^{\# \#}$ & $316.3 \pm 18.1^{\# \# * *}$ & $304.5 \pm 23.5^{\# \# * *}$ \\
\hline Week 8 & $218.4 \pm 15.5$ & $489.9 \pm 20.3^{\# \#}$ & $375.8 \pm 21.4^{\# \# * *}$ & $352.6 \pm 19.1^{\# \# * *}$ \\
\hline \multicolumn{5}{|c|}{ 8-OHdG (pg/mg protein) } \\
\hline Baseline & $810.7 \pm 32.6$ & $958.3 \pm 32.5^{\# \#}$ & $975.2 \pm 30.6^{\# \#}$ & $969.2 \pm 22.3^{\# \#}$ \\
\hline Week 4 & $816.7 \pm 35.4$ & $1398.2 \pm 33.7^{\# \#}$ & $1179.5 \pm 28.4^{\# \# *}$ & $1163.6 \pm 34.5^{\# \# * *}$ \\
\hline Week 8 & $823.1 \pm 30.4$ & $1757.8 \pm 21.9^{\# \#}$ & $1474.5 \pm 25.3^{\# \# * *}$ & $1365.3 \pm 28.6^{\# \# * *}$ \\
\hline \multicolumn{5}{|c|}{ SOD (U/mg protein) } \\
\hline Baseline & $60.8 \pm 4.8$ & $49.3 \pm 7.1^{\#}$ & $50.4 \pm 5.5^{\#}$ & $49.9 \pm 6.2^{\#}$ \\
\hline Week 4 & $61.3 \pm 7.1$ & $34.2 \pm 7.2^{\# \#}$ & $43.5 \pm 3.5^{\# *}$ & $44.9 \pm 4.3^{\# *}$ \\
\hline Week 8 & $59.1 \pm 5.2$ & $30.4 \pm 4.7^{\# \#}$ & $38.6 \pm 6.4^{\# * *}$ & $41.4 \pm 3.6^{\# * *}$ \\
\hline \multicolumn{5}{|c|}{ MDA (nM/mg protein) } \\
\hline Baseline & $14.6 \pm 4.4$ & $16.8 \pm 3.3^{\#}$ & $16.4 \pm 3.7^{\#}$ & $16.7 \pm 5.6^{\#}$ \\
\hline Week 4 & $15.3 \pm 3.7$ & $23.6 \pm 3.5^{\#}$ & $19.8 \pm 1.6^{\# *}$ & $18.5 \pm 4.3^{\# * *}$ \\
\hline Week 8 & $15.7 \pm 1.2$ & $28.7 \pm 4.1^{\#}$ & $22.6 \pm 2.9^{\# *}$ & $21.2 \pm 5.3^{\# *}$ \\
\hline \multicolumn{5}{|c|}{ CAT (U/mg protein) } \\
\hline Baseline & $26.2 \pm 2.2$ & $23.0 \pm 1.4^{\#}$ & $23.3 \pm 2.3^{\#}$ & $23.1 \pm 2.8^{\#}$ \\
\hline Week 4 & $26.4 \pm 1.2$ & $15.9 \pm 2.9^{\# \#}$ & $21.5 \pm 1.7^{\# * *}$ & $21.3 \pm 2.1^{\# * *}$ \\
\hline Week 8 & $25.1 \pm 1.8$ & $13.6 \pm 2.7^{\# \#}$ & $17.4 \pm 1.5^{\# *}$ & $18.3 \pm 2.4^{\# * *}$ \\
\hline \multicolumn{5}{|c|}{ 3-nitrotyrosine $(\mu \mathrm{g} / \mathrm{mL})$} \\
\hline Baseline & $18.7 \pm 2.8$ & $20.4 \pm 1.1^{\#}$ & $20.3 \pm 1.0^{\#}$ & $21.1 \pm 2.4^{\#}$ \\
\hline Week 4 & $18.5 \pm 2.6$ & $29.5 \pm 3.3^{\# \#}$ & $24.8 \pm 0.9^{\# *}$ & $22.3 \pm 1.8^{\# *}$ \\
\hline Week 8 & $20.4 \pm 3.1$ & $36.7 \pm 2.8^{\# \#}$ & $30.2 \pm 1.5^{\# *}$ & $31.4 \pm 2.7^{\# *}$ \\
\hline
\end{tabular}

Note: normal, C57BLKS/J normal nontreated mice; control, C57BLKS/J db/db nontreated mice; EGCG A, db/db mice treated with EGCG of 50 mg/kg/d; EGCG $\mathrm{B}, \mathrm{db} / \mathrm{db}$ mice treated with EGCG of $100 \mathrm{mg} / \mathrm{kg} / \mathrm{d}$; ROS, reactive oxygen species; 8-OHdG, 8-hydroxy-2 ${ }^{\prime}$-deoxyguanosine; SOD, superoxide dismutase; CAT, catalase; MDA, malondialdehyde. ${ }^{\#} P<0.05$ and ${ }^{\# \#} P<0.01$ versus normal; ${ }^{*} P<0.05$ and ${ }^{*}{ }^{*} P<0.01$ versus control; values are means \pm SEM. At baseline and at week $4, n=16$ in each group; at week $8, n=8$ in each group.

renoprotective effects of EGCG, we performed a cell-based study in HK-2 cells. Based on our results, EGCG could downregulate the expression of several factors involved in Ang II mediated oxidative stress in kidney including NOX-1, NOX-4, p22-phox, p47-phox, p-ERK1/2, p-P38 MAPK, TGF$\beta 1$, and $\alpha$-SMA. EGCG is supposed to play a role in Ang II induced renal injury similar to PD98059 and SB202190, both of which are blockers of downstream molecules of Ang II pathway.

Considering the effects of EGCG in Ang II mediated oxidative stress in DKD in our study, we plotted a diagram elucidating the possible function of EGCG in Ang II regulated pathways, as shown in Figure 8. The renoprotective effects of EGCG might be realized by two pathways: one is functioning as a NADPH oxidase inhibitor, directly suppressing the production of ROS, and the other is inhibiting the expression of downstream molecules of Ang II mediated pathway, directly downregulating the production of effectors for renal fibrosis. Other possible mechanisms of EGCG such as function as an AT-1R blocker should be explored in further studies.

In summary, our results suggested that EGCG has renoprotective effects in diabetic $\mathrm{db} / \mathrm{db}$ mice through disturbing Ang II mediated oxidative stress. These effects of EGCG are realized by several mechanisms including directly

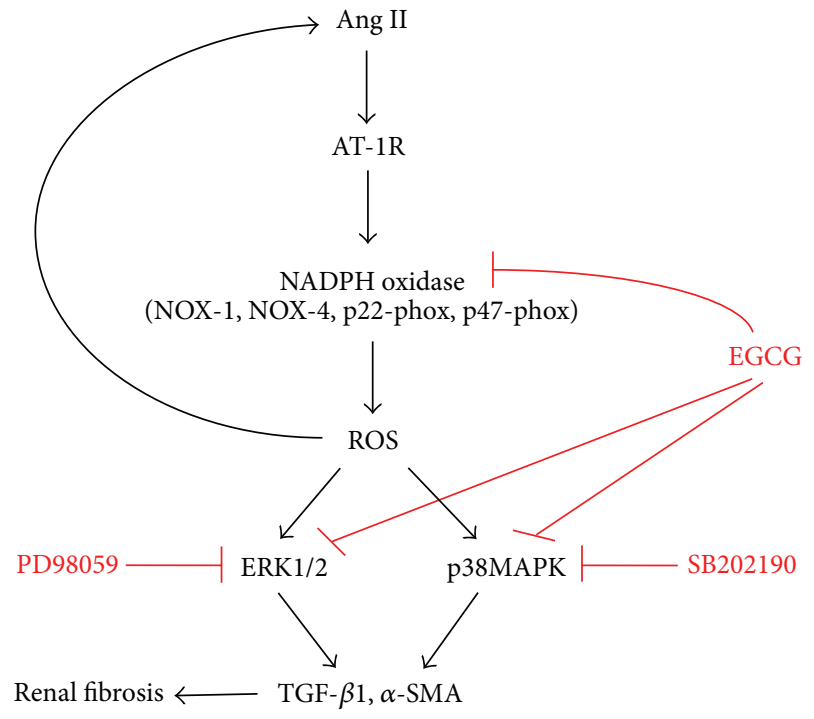

FIGURE 8: Diagram of the underlying mechanisms of EGCG disturbing Ang II induced oxidative stress and renal fibrosis.

suppressing the activity of NADPH oxidase and inhibiting MAPK cascade involved in Ang II pathway. 


\section{Competing Interests}

The authors declare that there are no competing interests.

\section{Authors' Contributions}

Xiu Hong Yang and Yu Pan contributed equally to this paper.

\section{Acknowledgments}

The study was supported by the Key Specialized Construction Project in Medicine of Shanghai (ZK2015A15), the Key Discipline Construction Project of the Pudong Health Bureau of Shanghai (PWZx2014-11), Outstanding Leaders Training Program of the Pudong Health Bureau of Shanghai (PWRI201205), the Shanghai Committee on Science and Technology (15ZR1437400), and grants from the National Natural Science Foundation of China (no. 81300652) for research resources.

\section{References}

[1] International Diabetes Federation, IDF Diabetes Atlas, International Diabetes Federation, Brussels, Belglum, 7th edition, 2015, http://www.diabetesatlas.org/.

[2] F. A. Hakim and A. Pflueger, "Role of oxidative stress in diabetic kidney disease," Medical Science Monitor, vol. 16, no. 2, pp. A37A48, 2010.

[3] S. Tesfaye, L. Vileikyte, G. Rayman et al., "Painful diabetic peripheral neuropathy: consensus recommendations on diagnosis, assessment and management," Diabetes/Metabolism Research and Reviews, vol. 27, no. 7, pp. 629-638, 2011.

[4] R. C. Stanton, "Oxidative stress and diabetic kidney disease," Current Diabetes Reports, vol. 11, no. 4, pp. 330-336, 2011.

[5] Y. Gorin and F. Wauquier, "Upstream regulators and downstream effectors of NADPH oxidases as novel therapeutic targets for diabetic kidney disease," Molecules and Cells, vol. 38, no. 4, pp. 285-296, 2015.

[6] J. M. Forbes, M. T. Coughlan, and M. E. Cooper, "Oxidative stress as a major culprit in kidney disease in diabetes," Diabetes, vol. 57, no. 6, pp. 1446-1454, 2008.

[7] E. A. Jaimes, P. Hua, R.-X. Tian, and L. Raij, "Human glomerular endothelium: interplay among glucose, free fatty acids, angiotensin II, and oxidative stress," American Journal of Physiology-Renal Physiology, vol. 298, no. 1, pp. F125-F132, 2010.

[8] K. Fukami, S. Ueda, S.-I. Yamagishi et al., "AGEs activate mesangial TGF- $\beta$-Smad signaling via an angiotensin II type I receptor interaction," Kidney International, vol. 66, no. 6, pp. 2137-2147, 2004.

[9] K. Chopra, V. Tiwari, V. Arora, and A. Kuhad, "Sesamol suppresses neuro-inflammatory cascade in experimental model of diabetic neuropathy," The Journal of Pain, vol. 11, no. 10, pp. 950957, 2010.

[10] M.-L. Brezniceanu, F. Liu, C.-C. Wei et al., "Attenuation of interstitial fibrosis and tubular apoptosis in $\mathrm{db} / \mathrm{db}$ transgenic mice overexpressing catalase in renal proximal tubular cells," Diabetes, vol. 57, no. 2, pp. 451-459, 2008.

[11] H. B. Lee, M.-R. Yu, Y. Yang, Z. Jiang, and H. Ha, "Reactive oxygen species-regulated signaling pathways in diabetic nephropathy," Journal of the American Society of Nephrology, vol. 14, no. 3, pp. S241-S245, 2003.
[12] S. Fang, Y. Jin, H. Zheng et al., "High glucose condition upregulated Txnip expression level in rat mesangial cells through ROS/MEK/MAPK pathway," Molecular and Cellular Biochemistry, vol. 347, no. 1-2, pp. 175-182, 2011.

[13] S. M. Nam, M. Y. Lee, J. H. Koh et al., "Effects of NADPH oxidase inhibitor on diabetic nephropathy in OLETF rats: the role of reducing oxidative stress in its protective property," Diabetes Research and Clinical Practice, vol. 83, no. 2, pp. 176-182, 2009.

[14] L. Luo, D.-Z. Dai, Y.-S. Cheng, Q. Zhang, W.-J. Yuan, and Y. Dai, "Sildenafil improves diabetic vascular activity through suppressing endothelin receptor A, iNOS and NADPH oxidase which is comparable with the endothelin receptor antagonist CPU0213 in STZ-injected rats," Journal of Pharmacy and Pharmacology, vol. 63, no. 7, pp. 943-951, 2011.

[15] M. Xu, D.-Z. Dai, and Y. Dai, "Normalizing NADPH oxidase contributes to attenuating diabetic nephropathy by the dual endothelin receptor antagonist CPU0213 in rats," American Journal of Nephrology, vol. 29, no. 3, pp. 252-256, 2009.

[16] H.-J. Jang, S. D. Ridgeway, and J.-A. Kim, "Effects of the green tea polyphenol epigallocatechin-3-gallate on high-fat dietinduced insulin resistance and endothelial dysfunction," American Journal of Physiology-Endocrinology and Metabolism, vol. 305, no. 12, pp. E1444-E1451, 2013.

[17] C. E. N. Reiter, J.-A. Kim, and M. J. Quon, "Green tea polyphenol epigallocatechin gallate reduces endothelin-1 expression and secretion in vascular endothelial cells: roles for AMP-activated protein kinase, Akt, and FOXO1," Endocrinology, vol. 151, no. 1, pp. 103-114, 2010.

[18] S. P. Yoon, Y. H. Maeng, R. Hong et al., "Protective effects of epigallocatechin gallate (EGCG) on streptozotocin-induced diabetic nephropathy in mice," Acta Histochemica, vol. 116, no. 8, pp. 1210-1215, 2014.

[19] R. Gao, Y. Wang, Z. Wu, J. Ming, and G. Zhao, "Interaction of barley $\beta$-glucan and tea polyphenols on glucose metabolism in streptozotocin-induced diabetic rats," Journal of Food Science, vol. 77, no. 6, pp. H128-H134, 2012.

[20] L. Elbling, R.-M. Weiss, O. Teufelhofer et al., "Green tea extract and (-)-epigallocatechin-3-gallate, the major tea catechin, exert oxidant but lack antioxidant activities," The FASEB Journal, vol. 19, no. 7, pp. 807-809, 2005.

[21] G.-X. Li, Y.-K. Chen, Z. Hou et al., "Pro-oxidative activities and dose-response relationship of (-)-epigallocatechin-3-gallate in the inhibition of lung cancer cell growth: a comparative study in vivo and in vitro," Carcinogenesis, vol. 31, no. 5, pp. 902-910, 2010.

[22] N. Yamabe, T. Yokozawa, T. Oya, and M. Kim, "Therapeutic potential of (-)-epigallocatechin 3-O-gallate on renal damage in diabetic nephropathy model rats," Journal of Pharmacology and Experimental Therapeutics, vol. 319, no. 1, pp. 228-236, 2006.

[23] J. Gu, X. Liu, Q.-X. Wang et al., "Angiotensin II increases CTGF expression via MAPKs/TGF- $\beta 1 /$ TRAF6 pathway in atrial fibroblasts," Experimental Cell Research, vol. 318, no. 16, pp. 2105-2115, 2012.

[24] D. Liu, J. T. Perkins, and B. Hennig, "EGCG prevents PCB-126induced endothelial cell inflammation via epigenetic modifications of NF- $\kappa$ B target genes in human endothelial cells," Journal of Nutritional Biochemistry, vol. 28, pp. 164-170, 2016.

[25] A. Peng, T. Ye, D. Rakheja et al., "The green tea polyphenol (-)epigallocatechin-3-gallate ameliorates experimental immunemediated glomerulonephritis," Kidney International, vol. 80, no. 6, pp. 601-611, 2011. 
[26] J. Yan, Y. Zhao, S. Suo, Y. Liu, and B. Zhao, "Green tea catechins ameliorate adipose insulin resistance by improving oxidative stress," Free Radical Biology and Medicine, vol. 52, no. 9, pp. 1648-1657, 2012.

[27] F. Pistrosch, J. Passauer, K. Herbrig, U. Schwanebeck, P. Gross, and S. R. Bornstein, "Effect of thiazolidinedione treatment on proteinuria and renal hemodynamic in type 2 diabetic patients with overt nephropathy," Hormone and Metabolic Research, vol. 44, no. 12, pp. 914-918, 2012.

[28] K. Reidy, H. M. Kang, T. Hostetter, and K. Susztak, "Molecular mechanisms of diabetic kidney disease," The Journal of Clinical Investigation, vol. 124, no. 6, pp. 2333-2340, 2014.

[29] Y. Li, G.-S. Shen, C. Yu et al., "Local bone interaction between renin-angiotensin system and kallikrein-kinin system in diabetic rat," International Journal of Clinical and Experimental Pathology, vol. 8, no. 2, pp. 1604-1612, 2015.

[30] H. Suzuki, T. Kikuta, T. Inoue, and U. Hamada, “Time to reevaluate effects of renin-angiotensin system inhibitors on renal and cardiovascular outcomes in diabetic nephropathy," World Journal of Nephrology, vol. 4, no. 1, pp. 118-126, 2015.

[31] D. A. Long, K. L. Price, J. Herrera-Acosta, and R. J. Johnson, "How does angiotensin II cause renal injury?" Hypertension, vol. 43, no. 4, pp. 722-723, 2004.

[32] J. R. Ingelfinger, "Preemptive olmesartan for the delay or prevention of microalbuminuria in diabetes," The New England Journal of Medicine, vol. 364, no. 10, pp. 970-971, 2011.

[33] A. P. Lakshmanan, R. A. Thandavarayan, K. Watanabe et al., "Modulation of AT-1R/MAPK cascade by an olmesartan treatment attenuates diabetic nephropathy in streptozotocininduced diabetic mice," Molecular and Cellular Endocrinology, vol. 348, no. 1, pp. 104-111, 2012.

[34] T. Kochi, M. Shimizu, D. Terakura et al., "Non-alcoholic steatohepatitis and preneoplastic lesions develop in the liver of obese and hypertensive rats: suppressing effects of EGCG on the development of liver lesions," Cancer Letters, vol. 342, no. 1, pp. 60-69, 2014.

[35] Y.-S. Han, L. Lan, J. Chu, W.-Q. Kang, and Z.-M. Ge, "Epigallocatechin gallate attenuated the activation of rat cardiac fibroblasts induced by angiotensin II via regulating $\beta$-arrestinl," Cellular Physiology and Biochemistry, vol. 31, no. 2-3, pp. 338346, 2013.

[36] A. A. Elmarakby and J. C. Sullivan, "Relationship between oxidative stress and inflammatory cytokines in diabetic nephropathy," Cardiovascular Therapeutics, vol. 30, no. 1, pp. 49-59, 2012.

[37] X. Y. Shi, F. Hou, H. X. Niu et al., "Advanced oxidation protein products promote inflammation in diabetic kidney through activation of renal nicotinamide adenine dinucleotide phosphate oxidase," Endocrinology, vol. 149, no. 4, pp. 1829-1839, 1829. 


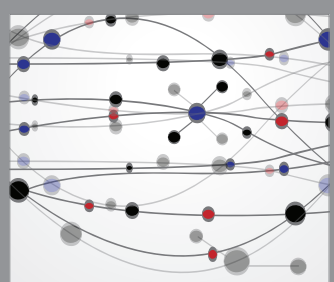

The Scientific World Journal
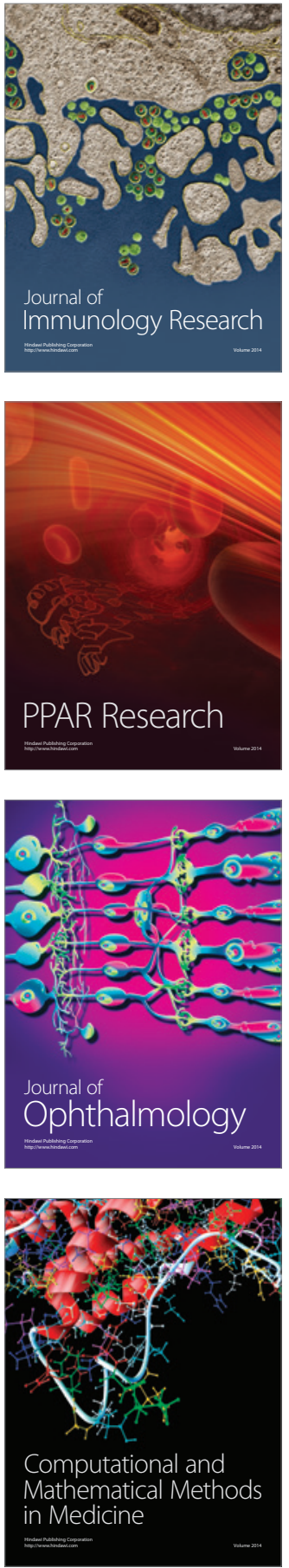

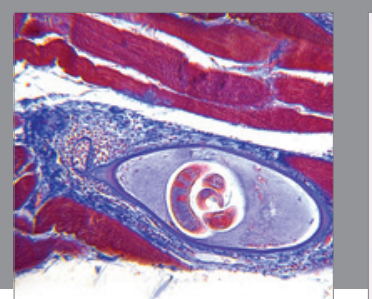

Gastroenterology Research and Practice

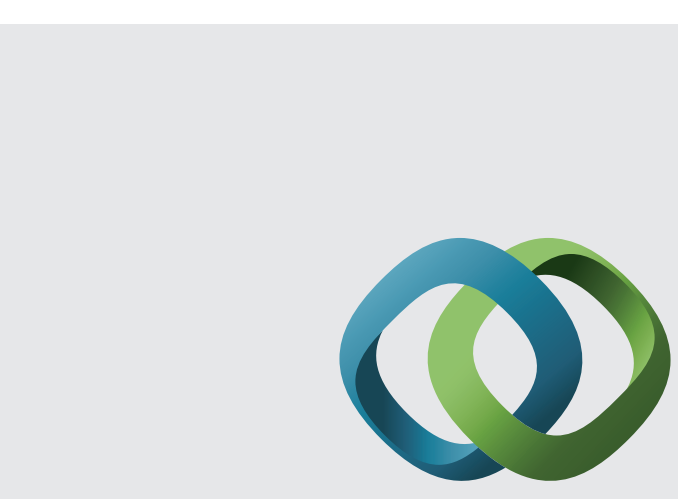

\section{Hindawi}

Submit your manuscripts at

http://www.hindawi.com
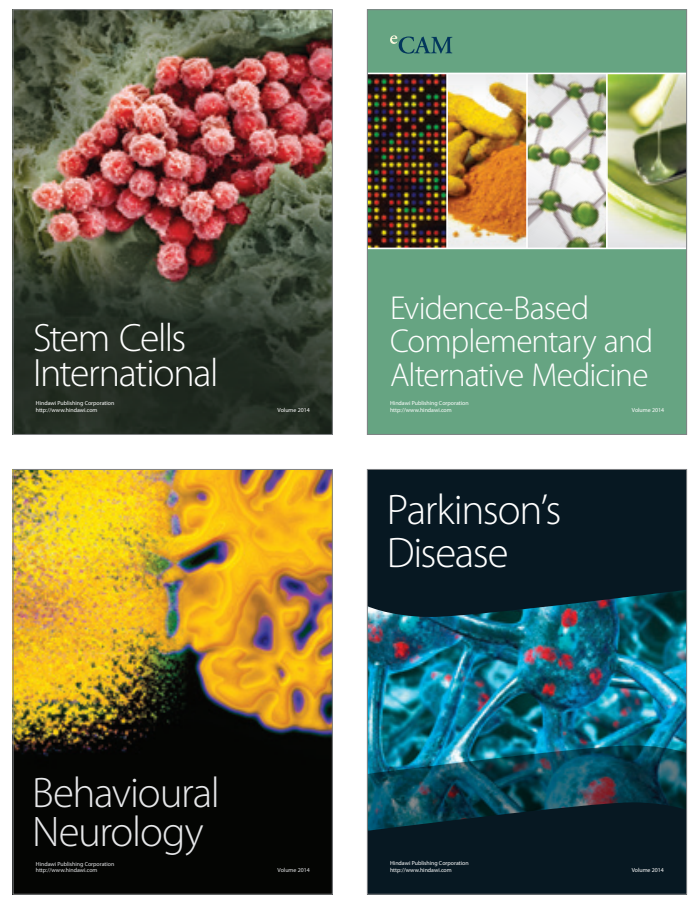
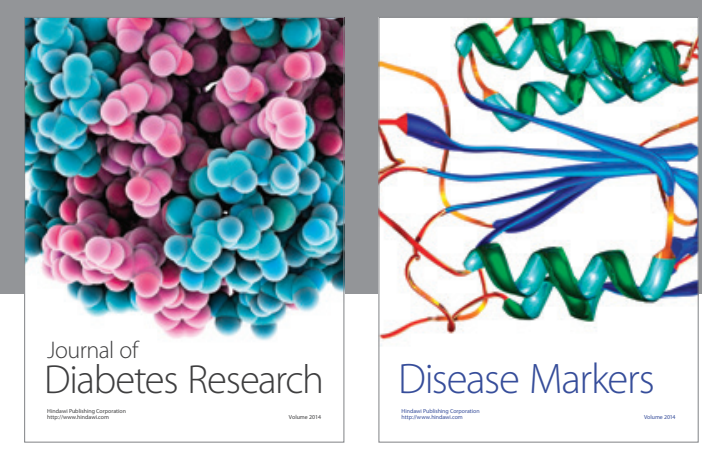

Disease Markers
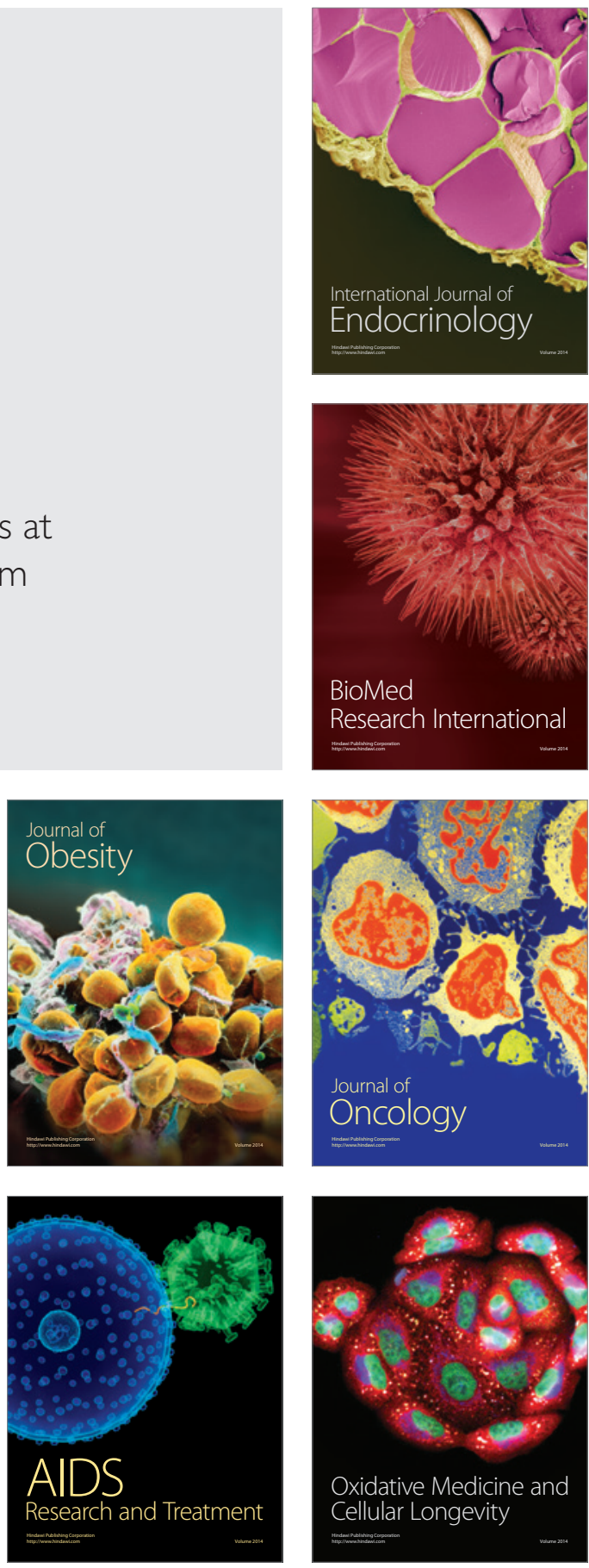